\title{
Uncertainty Analysis Routine for the Ocean Thermal Energy Conversion (OTEC) Biofouling Measurement Device and Data Reduction Procedure
}

by

S. P. Bird

March 1973

Pacific Northwest Laboratory Richland, Wasnington 99352

Operated for the U.S. Department of Energy by 


\title{
NOTICE
}

This report was prepared as an account of work sponsored by the United States Government. Neither the United States nor the Department of Energy. nor any of their employees, nor any of their contractors, subcontractors, or their employees, makes any warranty, express or implied, or assumes any legal liability or responsibility for the accuracy, completeness or usefulness of any information, apparatus, product or process disclosed, or represents that its use would not infringe privately owned rights.

The views, opinions and conclusions contained in this report are those of the contractor and do not necessarily represent those of the United States Government or the United States Department of Energy.

\author{
PACIFIC NORTHWEST LABORATORY \\ operated by \\ BATTELLE \\ for the \\ UNITED STATES DEPARTMENT OF ENERGY \\ Under Contract EY-76-C-06-7830
}
Printed in the United States of America
Available from
National Techinical information Service
United States Department of Commerce 5285 Port Royal Road
Springfield, Virginia 22151
Price: Printed Copy s_; Microliche $\$ 3.00$

NTIS

-Page; Selling Price

$001-025 \quad 54.50$

$026-050 \quad 55.00$

$\begin{array}{ll}057-075 & 55.50\end{array}$

$076-100=56.00$

$101-125 \quad 56.50$

$\begin{array}{ll}126-150 & 57.00\end{array}$

$751-175 \quad 5775$

$176 \cdot 200 \quad 58.50$

201-225 $\quad \$ \quad \$ 8.75$

$226-250 \quad 59.00$

$251.275 \quad 510.00$

$276-300 \quad 510.25$ 


\section{7}

UNCERTAINTY ANALYSIS ROUTINE FOR THE OCEAN THERMAL ENERGY CONVERSION (OTEC) BIOFOULING MEASUREMENT DEVICE AND DATA REDUCTION PROCEDURE

by

S. P. Bird

Apri1 1978

BATTELLE

Pacific Northwest Laboratories

Richland, Washington 99352 


\section{ACKNCWLEDGMENTS}

This report summarizes a study conducted at the Pacific Northwest Laboratory (PNL), operated by Battelle Memorial Institute for the Division of Solar Technology of the Department of Energy. Guidance for the report and contributions to Sections 1 and 2 were provided by Dr. W. W. Laity of PNL. Other PNL staff members providing valuable review and comments were Mr. J. M. Creer, Dr. A. M. Sutey, and lir. L. D. Perrigo. 


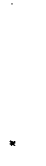

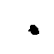


Biofouling and corrosion of heat exchanger surfaces in 0cean Thermal Energy Conversion (OTEC) systems may be controlling factors in the potential success of the OTEC concept. Very little is known about the nature and behavior of marine fouling films at sites potentially suitable for OTEC power plants. To facilitate the acquisition of needed data, a biofouling measurement device developed by Professor J. G. Fetkovich and his associates at Carnegie-Mellon University (CMU) has been mass produced for use by several organizations in experiments at a variety of ocean sites. The CMU device is designed to detect small changes in thermal resistance associated with the formation of marine microfouling films.

This report is an account of the work performed at the Pacific Northwest Laboratory (PNL) to develop a computerized uncertainty analys is for estimating experimental uncertainties of results obtained with the CMU biofouling measurement device and data reduction scheme. The analys is program was written as a subroutine to the CMU data reduction code and provides an alternative to the CMU procedure for estimating experimental errors.

The PNL code was used to analyze sample data sets taken at Keahole Point, Hawaii; St. Croix, the Virgin Islands; and at a site in the Gulf of Mexico. The uncertainties of the experimental results were found to vary considerably with the conditions under which the data were taken. For example, uncertainties of fouling factors (where fouling factor is defined as the thermal resistance of the biofouling layer) estimated from data taken on a submerged buoy at Keahole Point, Hawaij were found to be consistently within $0.00006 \mathrm{hr}-\mathrm{ft}^{2}-{ }^{\circ} \mathrm{F} / \mathrm{Btu}$, while corresponding values for data taken on a tugboat in the Gulf of Mexico ranged up to 0.0010 $\mathrm{hr}-\mathrm{ft}^{2}-{ }^{\circ} \mathrm{F} / \mathrm{Btu}$. Reasons for these differences are discussed in this report. 
ACKNOWLEDGMENTS SUMMARY.

1.0 INTRODUCTION

2.0 CONCLUSIONS AND RECOMMENDATIONS

3.0 DESCRIPTION OF CMU BIOFOULING DEVICE

3.1 MECHANICAL DESIGN .

3.2 HEAT TRANSFER THEORY.

4.0 CNU DATA ANALYSIS ROUTINE

\subsection{PROGRAM HTAU.}

4.2 PROGRAM HTCOEF .

5.0 PNL UNCERTAINTY ANALYSIS . . . . . . . . . . . . . . . . . 15

5.1 DEFINITION OF TERMS . . . . . . . . . . . . . . 16

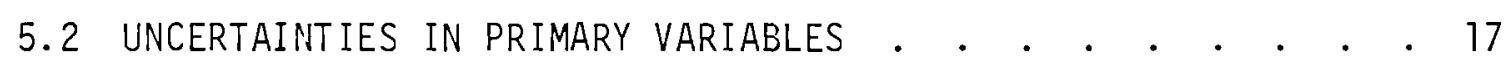

5.3 UNCERTAINTY ANALYSIS ROLTINE . . . . . . . . . . . 20

5.3.1 Thermopile Voltage . . . . . . . . . . . . 21

5.3.2 Water Temperature. . . . . . . . . . . . . 22

5.3 .3 Flow Rate. . . . . . . . . . . . . 23

5.3.4 Time Constant . . . . . . . . . . . . 24

5.3.5 Conductance Coefficient. . . . . . . . . . 25

5.3.6 Air Side Heat Loss Correction. . . . . . . . . 25

5.3.7 Tube Wall heat Loss Correction . . . . . . . . 25

5.3 .8 Temperature Normalization . . . . . . . . . 26

5.3.9 Velocity Normalization . . . . . . . . . . . . 26

\subsection{RESULTS .}

7.0 DATA REDUCTION AND UNCERTAINTY

ANALYSIS PROCEDURE LIMITAT IONS

7.1 WATER TEMPERATURE FluCtUATIONS. . . . . . . . . . 33

7.2 FLOW RATE FLUCTUATIONS . . . . . . . . . . . . 35

7.3 HTCOEF UNCERTAINTY PREDICTIONS. . . . . . . . . . . . 35

7.4 THERMAL ENTRY EFFECTS. . . . . . . . . . . . . 38

7.5 ApPARATUS FAILURES. . . . . . . . . . . . . . . . 40

7.6 DESIGN IMPROVEMENTS . . . . . . . . . . . . . . . . . 40

REFERENCES. . . . . . . . . . . . . . . . . . . . . . . . 43

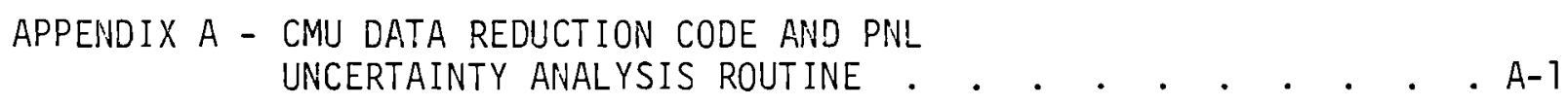

APPENDIX B - SAMPLE RESULTS . . . . . . . . . . . . . . . . B-1 
UNCERTAINTY ANALYSIS ROUTINE FOR THE OCEAN

THERMAL ENERGY CONVERSION (OTEC) BIOFOUL ING

MEASUREMENT DEVICE AND DATA REDUCTION PROCEDURE

\subsection{INTRODUCTION}

One concept that shows promise for using solar energy to meet the energy needs of mankind is Ocean Thermal Energy Conversion (OTEC). This technique would employ heat engines operating on the temperature differences between warm surface water and cold deep water of the oceans.

Because thermodynamic cycle efficiencies under these relatively small temperature differences are inherently very low, heat exchangers for closed-cycle OTEC systems would be exceptionally large and must maintain high performance characteristics. Under these conditions biofouling and corrosion of heat transfer surfaces become controlling factors that must be dealt with for successful long-term operation of heat exchangers in OTEC appiications.

Most of the OTEC research and development work in the United States is proceeding under the sponsorship of the Division of Solar Technology of the U.S. Department of Energy (DOE). Assistance to DOE in planning and managing the work necessary to identify, control, and alleviate biofouling and corrosion problems that might be encountered in OTEC systems is provided by a Biofouling and Corrosion Project Office established by the Battelle Memorial Institute at the Pacific Northwest Laboratory (PNL).

Although it is recognized that even thin fouling films of organic and/or inorganic substances on OTEC heat exchanger surfaces may seriously impede heat transfer, very little is known about the nature and behavior of fouling films at potential OTEC sites. (1) Experimental devices designed to detect small changes in thermal resistance are necessary for acquiring needed data on the heat transfer effects of marine microfouling films. One device of this type has been developed for the DOE-OTEC program by Professor J. G. Fetkovich and his associates at Carnegie-Mellon University (CMU), Pittsburgh, Pennsylvania. 
To facilitate the acquisition of a comprehensive, reliable biofouling data base, CMU devices have been mass produced for use by several organizations in experiments at sites in the Atlantic and Pacific Oceans and in the Gulf of Mexico. The Pacific Northwest Laboratory is one of the organizations prepared to process data from these experiments, using computer codes developed at CMU.

At the request of the Biofouling and Corrosion Project Office, an independent assessment of the CMU data acquisition system and data reduction scheme was performed at PilL. As part of this work, a computer code was developed to estimate uncertainties of the experimental results, using an approach that differs from the one used by CMU. The PNL code is appended as a subroutine to the CMU data reduction program, with the result that two independent estimates of the uncertainties are obtained.

This report describes the PNL uncertainty routine and the insights acquired during its development. Specific topics covered include the mechanical design and heat transfer theory of the CMU device, principal elements of the CMU data reduction scheme, details of the PNL uncertainty analysis routine, sample results using the routine, and limitations of both the CMU and PNL uncertainty analys is procedures. 


\subsection{CONCLUSIONS AND RECOMMENDATIONS}

The principal conclusions reached at PNL regarding the CMU computational scheme for reducing biofouling data, the PNL code for estimating uncertainties of the experimental results, and design features of the CMU device that affect the accuracy of the data are as follows:

- CMU Approach for Estimating Uncertainties: In the data reduction scheme developed at CMU, provisions are included for performing a statistical analysis of the results computed from a given set of data. This analysis yields an overall uncertainty that is inversely proportional to the square root of the number of repeated runs in the set of data. Thus, the value of the uncertainty computed in accordance with this approach decreases with an increase in the number of measurement replications. Investigations at PNL indicated that there are likely to be systematic (i.e., fixed) errors in the data acquisition system and data reduction scheme that cannot be reduced by increasing the number of repeated runs, and that, therefore, the statistical approach used by CMU may yield estimates that are unrealistically low. For this reason the PNL routine was written to provide uncertainty estimates that include the effects of uncertainties in the system instrumentation and data reduction procedure rather than basing the estimates entirely on a statistical analysis of the computed results.

- PNL Estimates of Fouling Factor Uncertainties: On the basis of estimates obtained with the PNL uncertainty analysis code, the uncertainties of experimental results determined from data taken with the CMU biofouling measurement device vary considerably with the conditions under which the device is operated. For five sets of data taken on a submerged buoy at Keahole Point, Hawaii, the uncertainties of fouling factors generally are within $0.00006 \mathrm{hr}-\mathrm{ft}^{2}-{ }^{\circ} \mathrm{F} / \mathrm{Btu}$. For five sets of data taken on a tugboat in the Gulf of Mexico, the uncertainties of fouling factors (where fouling factor is defined as the thermal resistance of the biofouling layer) range up to 0.00100 
$h r-f t^{2}-{ }^{\circ} \mathrm{F} /$ Btu. The former uncertainties are due primarily to rapid variations in ambient seawater temperature, while the latter are due primarily to fluctuations (induced by wave action on the tugboat) in flow through the test devices.

- Sources of Uncertainty in the CMU Biofouling Measurement Device: Sources of uncertainty inherent in the design of the device include those listed below. With the exception of the first, for which estimates can be obtained from the experimental data, these uncertainties are not accounted for in either the CMU data reduction scheme or the PNL uncertainty analysis code. Nevertheless, it is important to recognize that these uncertainties exist.

1. When operated under conditions that do not interfere with maintaining steady flow through the device, the largest source of uncertainty is the difference in transient responses of the heater cylinder and thermocouple reference cylinder to fluctuations in seawater temperature.

2. Between the heater cylinder and the seawater flowing through it are several thermal resistances in series. The one of primary interest is that due to the biofouling layer. Another is the contact resistance between the heater cylinder and the tube mounted within it. Even small changes in this contact resistance would be substantial relative to the sensitivity required to measure the biofouling resistance. A basic assumption made in the CMU data reduction scheme is that the contact resistance is invariant throughout an experiment. Any departure from this that actualiy occurs constitutes a substantial source of error, the magnitude of which cannot readily be ascertained.

3. One of the key variables measured in the device is the velocity of seawater flowing through it. Errors associated with biofouling and/or other deposits on the flowmeter are peculiar to the particular conditions under which the device is operated. Although they cannot readily be estimated, the uncertainty associated with flowmeter fouling could be substantial. 
4. A lesser source of uncertainty is that associated with development of a thermal boundary layer in the seawater flowing through the portion of the tube around which the heater cylinder is mounted. Temperature measurements taken at the heater cylinder are used to compute an overall thermal conductance, which includes the combined effects of heat transfer by convection to the flowing fluid and heat transfer by conduction across the fouling layer. Because the thermal boundary layer is not fulty developed, the local convective heat transfer coefficient varies as a function of position along the flow path through the cylinder. Consequently, the overall thermal conductance in this region differs from the thermal conductance of primary interest--that for a fully developed thermal boundary layer in the flow field. Moreover, the discrepancy between the two is not constant as a function of fouling film thickness (for reasons discussed in Section 7 of this report), and therefore this discrepancy varies with time during an experiment.

The development of an uncertainty analysis procedure at PNL suggested several aspects of the CMU device that should be investigated as potential areas for design or operating procedure improvement:

- Matching the thermal time constants of the copper heater and reference cylinders.

- Measuring the overall conductance coefficient in a region with a fully developed thermal boundary layer.

- Reducing spurious flowmeter voltage signals caused by rapid water flow rate fluctuations.

- Measuring flow rate without introducing excessive mechanical elements to the flow stream which are overly susceptible to biofouling and corrosion.

- Developing a flow measurement procedure that permits regular monitoring of the flowmeter zero-flow voltage. 
- Conducting pre- and post-experiment convective coefficient versus velocity tests (Wilson plots) to reveal any variation in cylinder-totube contact resistance. 


\subsection{DESCRIPTION OF CMU BIOFOULING DEVICE}

This section summarizes some of the pertinent background information concerning the Carnegie-Mellon University biofouling measurement device. The device has been described in detail in papers by Professor J. G. Fetkovich and his associates $(2,3)$ and, therefore, only a brief description is included here to lend clarity to the subsequent discussion of the PNL uncertainty analysis. The topics covered in this section are the mechanical design and underlying heat transfer theory of the system.

\subsection{MECHANICAL DESIGN}

The CMU biofouling apparatus provides a means for determining heat transfer conductances (a) by measuring the temperature decay in a preheated hollow copper cylinder surrounding a section of heat exchanger tube. The main components of the device are a 6-foot length of sample OTEC heat exchanger tube, a 1-foot long copper heater cylinder, a small copper reference cylinder, and a target type flowmeter. A simplified drawing is shown in Figure 1.

Seawater is pumped through the tube at a constant nominal velocity. The flowmeter records the actual time-dependent variations in this value so that the final value of the heat transfer conductance may be velocity normalized. The temperature sensing device in the copper cylinder is an 11-pair, iron-Constantan thermopile. Sensing junctions of the thermopile are located in the heater cylinder; the reference junctions are located in the smaller copper reference cyclinder. The reference cylinder remains at approximately ambient water temperature so the thermopile gives a direct output of the temperature difference between the heater cylinder and flowing

\footnotetext{
(a) CMU uses the term "convective heat transfer coefficient" in this context. $(2,3)$ The quantity actually determined is the combined thermal conductance due to convective heat transfer to the flowing water and conductive heat transfer across the biofouling layer. Therefore, this report uses the term "conductance" to describe this quantity and expresses it in variable form as capital $H$ rather than the lower case $h$ traditionally reserved for the convective heat transfer coefficient.
} 


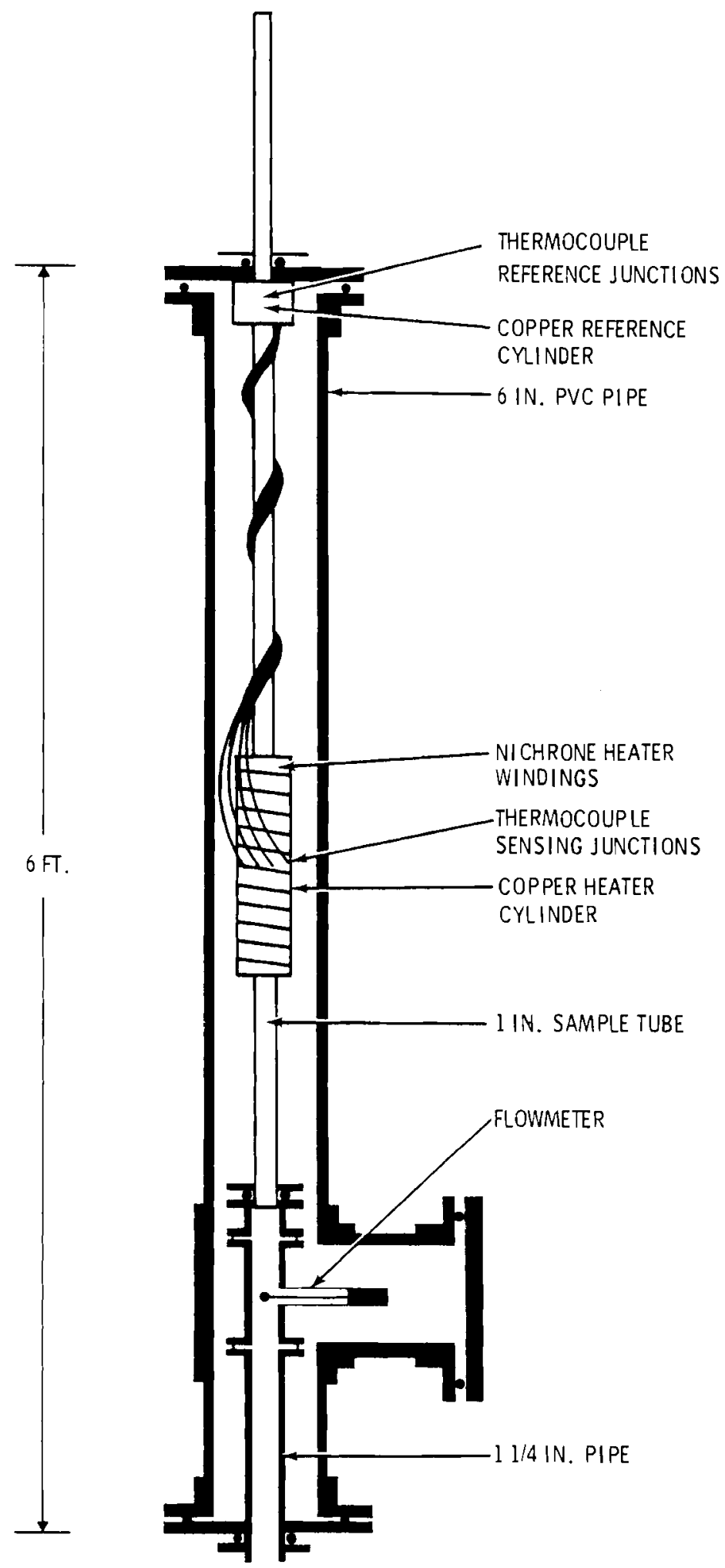

FIGURE 1. CMU Biofouling Measurement Device 
water. A thermistor is also attached to the tube to record the actual water temperature. These data are used for subsequent temperature normalization of the calculated heat transfer conductance.

During a data collection run the heater cylinder temperature is raised 1 to $3^{\circ} \mathrm{C}$ above water temperature with a nichrome wire resistance heater on the outer circumference. After the cylinder reaches steady state the heater is turned off and the temperature decay curve recorded.

\subsection{HEAT TRANSFER THEORY}

For the simplified case of uniform material from the outside of the heater cylinder to the inside of the heat exchanger tube and negligible thermal resistivity in this assembly, the temperature decay follows the familiar exponential decay pattern. Introduction of two materials (copper in the heater cylinder and various heat exchanger tube materials) and finite thermal conductivities makes the solution more complex. CMU investigators have derived the exact solution for this case, an infinite series involving exponential and Bessel functions. However, their analysis shows that for times longer than a few seconds the decay curve is almost exactly modeled by a single exponential term with a slightly modified time constant. (3, p. 34) Therefore, this latter approach is used in the CMU data reduction scheme to calculate a heat transfer conductance coefficient from the experimental1y determined temperature decay time constant.

One other consideration should be mentioned when discussing the heat transfer theory of the CMU device. There are several paths by which energy can be transferred out of the heater cylinder other than the primary one, to the seawater flowing through the heat exchanger tube. These secondary heat losses could cause the decay behavior of the heater cylinder to deviate from the theoretical model previously discussed. The CMU investigators point out that only two are significant--heat loss to the air side (outer side) of the heater cylinder and axially through the tube walls directly above and below the heater cylinder. $(3, p .42)$ CMU derived corrections to the calculated heat transfer conductance for each of these losses and the corrections were incorporated into the data reduction routine. 


\subsection{CMU DATA ANALYSIS ROUTINE}

The CMU data reduction scheme uses the thermopile temperature decay data to calculate a thermal decay time constant, converts this time constant into a combined heat transfer conductance coefficient, corrects the conductance for secondary heat losses, and, finally, uses thermistor and flowmeter data to normalize the calculated conductance to nominal operating conditions. This procedure is performed in a two-step process using two computer programs, HTAU and HTCOEF. The preliminary code HTAU utilizes geometric quantities and constant thermal properties of a test unit to determine the relationship between the time constant (TAU) and the conductance coefficient $(H)$ for that unit. It expresses this relationship as a third order polynomial and determines the curve fit coefficients. HTCOEF, the general data analysis routine, uses the three types of test unit data--thermopile voltage, thermistor voltage, and flowmeter voltage-and the curve fit parameters from HTAU to calculate the conductance coefficient. The computational procedures used in these codes are described in the following two subsections.

\section{1 PROGRAM HTAU}

The mathematical relationship between a time constant and a conductance coefficient depends only on the physical properties of a test unit. Therefore, this relationship can be determined before any data are taken and must be done only once for a specific unit.

The program HTAU carries out this task. In the first part of the program a series of sample heat transfer conductances is generated varying from 150 to $20508 \mathrm{tu} / \mathrm{hr}-\mathrm{ft}^{2}-{ }^{\circ} \mathrm{F}$. For each value the program then uses an iteration technique to determine the zeroes of the transcendental equation resulting from the application of the appropriate boundary conditions to the heat transfer model. (2, equation 3 ) These zeroes are used to calculate the time constant corresponding to each conductance coefficient. 
Using the matched pairs of time constants and conductance coefficients, the subroutines RELATN, COEFS, and ORTHLS calculate the coefficients for a polynomial curve fit of the form

$$
(\ell n H)=a+b(\ell n T A U)^{2}+c(\ell n T A U)^{2}+d(\ell n T A U)^{3}
$$

The main program then calls the subroutine EXIT to calculate the root mean square deviation of the curve fit points and print the results. The other subroutines in the code are used to evaluate the transcendental function $(F)$, calculate the first-term coefficients for the series expansion of the cylinder temperature distribution ( $R A R B$ ), and evaluate the Bessel functions used throughout the program (BSSL, BSSY, BESS, and GAMMA).

\subsection{PROGRAM HTCOEF}

The program HTCOEF is the general analysis code used to reduce the data from a test unit. Input consists of the thermopile, thermistor, and flowmeter voltage records for each run, the curve fit coefficients from HTAU, and various physical parameters describing the unit from which the data were obtained.

In the first step, HTCOEF reads an identifying number for the test unit to be analyzed. It then calls the subroutine LKTBLE which provides information pertinent to this unit to the main program.

HTCOEF next reads the three sets of input voltage data. Thermopile voltage data are analyzed first to determine the voltage output when there is no temperature difference between the heater and reference cylinders. This is done by calculating the mean of the last $N$ data points (where $N$ is specified in the program) at the asymptotic end of the thermopile decay curve. A standard deviation of these values is also calculated to be used later in the curve fitting routine. The raw thermopile data points are then adjusted for this zero-point value.

Because the heater cylinder temperature decay (or voltage decay) is almost exactly exponential, a plot of the natural logarithm of thermopile voltage versus time yields a straight line with a slope equal to the 
reciprocal of the time constant. The main program calls the subroutine LINFIT to calculate this slope in a two-step process. In the first step LINFIT arrives at an approximate time constant by analyzing the entire thermopile decay curve. The second iteration determines the final value of the time constant by analyzing the data in a narrow "window". This window begins a few seconds after the initial decay of the thermopile voltage curve (the length of the delay is specified in the program) and lasts for a period equal to $N$ times the approximate time constant from the first pass (where $N$ is specified in the program).

In the next few steps HTCOEF uses the thermistor voltage and flowmeter voltage data to calculate water temperature and flow velocity. It also determines the mean and standard deviation for each of these quantities.

The main program then calls the subroutine CCN which carries out the major data reduction procedure. It first uses the curve fit coefficients determined in HTAU to calculate a conductance coefficient according to the relation

$$
H=\exp \left[a+b(\ln T A U)+c(\operatorname{lnTAU})^{2}+d(\operatorname{lnTAU})^{3}\right]
$$

CCN adds corrections to the conductance coefficient which are required because of the approxinate nature of the heat transfer model in HTAU. It adjusts $H$ for heat loss to the air side (outer side) of the heater cylinder and for axial conduction through the tube walls immediately above and below the heater cylinder. Using the mean values for water temperature and flow velocity, CCN normalizes the value of $\mathrm{H}$ for a water temperature of $70^{\circ} \mathrm{F}$ and a velocity equal to the nominal velocity for the unit.

At this point, control returns to the main program and results of the current run are stored by subroutine STORE. After the entire procedure has been repeated for each run in the data set the main program calls the subroutine RESULT to calculate the mean conductance coefficient and the standard deviation in the mean. 


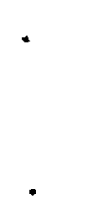




\subsection{PNL UNCERTAINTY ANALYSIS}

The original Carnegie-Mellon University data reduction code, HTCOEF, contains a limited error analysis. It is statistical in nature; uncertainties in various quantities are estimated by calculating root mean square deviations in the data spread. The stated uncertainty for the final, averaged value of the combined heat transfer conductance is also calculated by a statistical averaging process on the uncertainty results from individual runs.

The CMU approach for assigning uncertainties to the calculated conductance coefficient is completely correct only when at least three conditions apply: 1) the individual run values for $\mathrm{H}$ must follow a normal error distribution; 2) a sufficient number of runs must be completed so that the data points accurately reflect the parent population; and 3) no constant instrumental errors can be present which might bias the entire sample. Because it is difficult to assure these provisions have been met, the PNL uncertainty analysis was written with a different approach, one widely used for limited sample experiments in engineering applications. (4) This method involves three basic steps:

1. estimate the uncertainty in each directly measured quantity,

2. calculate the effect of each component uncertainty on the final result, and

3. combine each of these effects to find the total uncertainty in the final result.

The PNL uncertainty analysis was written as a subroutine (ERROR) to the original CMU data analysis program and runs in conjunction with it. This coupling was necessary because of the need for data input to the error analysis from various stages of the data reduction routine. No changes were made in the logic of HTCOEF to accommodate the error analysis subroutine so a complete computer run yields an unchanged statistical "error analysis" according to the CMU program as well as the PNL error analysis output. In some instances the PNL routine uses uncertainty values calculated in HTCOEF; in others it calculates alternative values. 
The probability basis, or confidence level, for the PNL uncertainty analysis is $95 \%$ (19 to 1 odds). For cases in which a statistical analysis of data fluctuations was used to estimate possible errors, a value of two standard deviations was used to provide the $95 \%$ confidence level in the stated uncertainty.

\subsection{DEFINITION OF TERINS}

To clarify the following discussion of the uncertainty analysis, it wi 11 be beneficial to define a number of terms as they are used in this project. "Variable" refers to any quantity measured directly during a data run. Variables could also be described as data, measurands, or independent variables. Secondary quantities calculated from variables are labeled "results". The term result need not necessarily refer to the final answer; there may be many intermediate results in the data analysis routine.

"Error" and "deviation" are synonymous and refer to the difference between any experimentally measured variable or result and its "true value". "Uncertainty" is the possible error. Since the probability basis for this error analysis is $95 \%$, it can be said that the error will be less than the uncertainty $95 \%$ of the time (or that a variable or result should be within its uncertainty from the true value $95 \%$ of the time).

"Accuracy" describes the closeness of the absolute value of a variable or result to its true value. "Precision" is a measure of how exactly the quantity can be determined without regard to its absolute value. It is also a measure of how reproducible the measurement is and is, therefore, analogous to the term "repeatability". Because uncertainty, as defined, includes the total deviation from all causes it takes into account both accuracy and precision.

Uncertainties in the variables and results can be caused by two kinds of errors. "Fixed errors" are those which are constant for a given procedure. They may result from inherent characteristics of the equipment or the use of approximate theories in calculating results. "Random errors" vary from reading to reading; electronic noise and drift are examples. 


\subsection{UNCERTAINTIES IN PRIMARY VARIABLES}

The first step in the error analysis was to assign uncertainties to the three major variables--thermopile voltage, thermistor voltage, and flowmeter voltage. Although not strictly variables, there are other quantities that enter into the analysis on the primary level and have associated uncertainties. These include the uncertainties due to curve fitting operations, calibrations, and various corrections and normalizations which are applied to the conductance coefficient. There are significant uncertainties, then, in the following primary quantities:

- thermopile voltage (VTC)

- therristor voltage (VTH)

- flowmeter vol tage (VFM)

- polynomial coefficients from HTAU (a, b, c, d)

- thermistor calibration coefficients (THINT, THSLP)

- flowmeter calibration coefficient (AVOLFM)

- air side heat loss correction (RAIR)

- tube wall heat loss correction (RWALLS)

- temperature normalization equation

- slope of $1 / \mathrm{h}$ versus $1 / \mathrm{V}^{0.8}$ plot used in velocity normalization equation (HRSLPE).

One cause of uncertainty for all three of the voltage signals is the electronic components used to transmit and condition them. Each of these signals passes through three basic components before it is recorded; it is amplified, converted to a digital signal for transmission, and converted back to an analog signal before being read. Some of the possible sources for uncertainty in these components are temperature-and time-dependent drift and electronic noise in the amplifiers and nonlinearity in the signal converters. The CMU data acquisition system uses high quality components so that these problems can be minimized, but they still exist, to different extents, in each of the variables. 
Electronic signal processing can introduce both random and fixed errors in each of the three voltage signals. For the PNL uncertainty analysis, these two sources of error are evaluated by different techniques. Random errors are estimated by observing the fluctuations in actual data. This is not possible with fixed errors, so they are predicted by a theoretical analysis of the data acquisition components.

Because the data analysis procedure requires only calculation of the slope of the thermopile decay curve, the absolute value of the thermopile voltages (VTC) is not important. This means that fixed, or bias, errors have no effect and only short-term random fluctuations in the signal are significant.

For thermistor voltages (VTH) the absolute value and, therefore, fixed errors are important. The magnitude of the fixed errors is estimated from the long-term drift of the thermistor circuit amplifier and nonlinearity in the signal converters. This value is described as the thermistor drift voltage (DRFVTH) in the PNL uncertainty routine.

Flowmeter voltage data have been handled in two distinct manners in the experiments utilizing the CMU device. In the early stages of the Keahole Point operation, a zero-flow flowmeter voltage was recorded at the beginning of each run. This practice eliminated long-term drift as a source of uncertainty. More recently in Hawaij and during the entire St. Croix and Gulf of Mexico operations, the zero-flow flowmeter reading was measured only at the commencement of the biofouling experiment. To analyze these cases the PNL uncertainty routine used an analytically derived value for the flowmeter voltage drift (DRFVFM).

The curve fit coefficients generated in the program HTAU also present a possible source of error. The optimal treatment of this problem would be to calculate the uncertainty in each individual coefficient, but this is quite unwieldy for a third-order equation. Instead, the total uncertainty is assigned to one parameter $(\triangle F I T)$ and is estimated from the curve fit root mean square deviation calculated in HTAU. 
Uncertainties for the thermistor and flowmeter calibration coefficient variables are evaluated by analyzing the original calibration data for each experimental unit. A computer curve-fitting routine determines the slope and intercept for the thermistor relation and the uncertainty in each ( $\triangle T H S, \triangle T H I$ ) as well as the magnitude and uncertainty ( $\triangle A V O)$ of the flowmeter calibration coefficient. In each case the uncertainty is assigned a value of twice the standard deviation of the curve fit coefficients.

The remaining primary sources of uncertainty associated with the data analysis procedure result from the corrections and normalizations of the calculated heat transfer conductance. CMU predicts an uncertainty in the air side convection and tube wal1 conduction heat loss corrections of $10 \%$. This value was deemed reasonable for tube wall conduction losses and was used in the PNL uncertainty analysis (ERWLS). The air side heat losses result from free convection and an uncertainty of 10\% seems unrealistically low in this case. One source in the heat transfer literature ${ }^{(5)}$ estimates that free convection coefficients can be estimated with an accuracy no better than $20 \%$, so it is unlikely that the total correction has an uncertainty less than 25\%. Because the air side correction is so small $(\approx 1 \%)$ the difference in its uncertainty between $10 \%$ and $25 \%$ is largely insignificant. Nevertheless, the PNL uncertainty analysis uses the $25 \%$ figure (ERAIR).

The temperature normalization equation used in HTCOEF was obtained from Baumeister and Marks' Standard Handbook for Mechancial Engineers. It appears in this source without documentation so it was impossible to accurately predict the associated uncertainty. In light of this, a conservative value of $1 \%$ uncertainty has been used (ERNOR). The final calculation in HTCOEF involves a normalization of the calculated heat transfer conductance to conform to the nominal flow velocity of the unit being analyzed. This is accomplished by using the slope (HRSLPE) of a $1 / \mathrm{h}$ versus $1 / \mathrm{N}^{0.8}$ curve calculated for the pertinent unit from previous data. The uncertainty in this slope (AHRS) used in the error analys is was also obtained from these curves. 
Each of the primary uncertainties discussed in this section was estimated as accurately as possible based on design data for the CMU biofouling device. An effort was made to ensure that the PNL uncertainty subroutine can be easily modified to incorporate changes in the CMU design. Unit-dependent uncertainties ( $\triangle T H I, \triangle T H S, \triangle A V O, \triangle F I T$, and $\triangle H R S$ ) are specified in the unit data subroutine, LKTBLE. General uncertainties associated with system electronics (DRFVTH, DRFVFil) and correction and normalization calculations (ERWLS, ERAIR, ERNOR) are specified in FORTRAN DATA statements in the PNL uncertainty anaTysis subroutine, ERROR. In this manner any of the primary uncertainties can be modified to apply to alternative equipment configurations having different electronics, calibrations, or components.

\subsection{UNCERTAINTY ANALYSIS ROUTINE}

The actual procedure followed, and equations used, by the uncertainty analysis will now be presented in some detail. The process is basically as described in Steps 2 and 3 in the introduction to this section. The effect of one variable on a subsequent result can be calculated by partial differentiation of the latter quantity with respect to the former. For a result which is a function of several independent variables, statistical theory indicates that the total uncertainty can be approximated by the square root of the sum of the individual effects. ${ }^{(4)}$ For example, for a function $A$ of three variables $x, y$, and $z$ :

$$
\begin{aligned}
A & =A(x, y, z) \\
\Delta A & =\sqrt{\left\{\frac{\partial A}{\partial x} \Delta x\right\}^{2}+\left\{\frac{\partial A}{\partial y} \Delta y\right\}^{2}+\left\{\frac{\partial A}{\partial z} \Delta z\right\}^{2}}
\end{aligned}
$$

In the PIL routine this process is repeated for each intermediate result so that the uncertainty in the final value of the heat transfer conductance wi 11 reflect all of the primary variable uncertainties. 
The routine calculates uncertainties in a step-by-step process for nine intermediate results:

1. thermopile voltage

2. water temperature

3. flow velocity

4. decay time constant

5. preliminary conductance coefficient

6. conductance coefficient after air side heat loss correction

7. conductance coefficient after tube wall heat loss correction

8. conductance coefficient after temperature normalization

9. conductance coefficient after velocity normalization.

\subsubsection{Thermopile Voltage}

The thermopile voltage data during the decay transient are adjusted by a zero temperature difference value according to the relation

$$
V T C=V T C_{x}-V T C_{0}
$$

VTC $C_{0}$ is calculated by averaging a specified number (NZERO) of zero temperature difference voltage values near the asymptotic end of the thermopile decay curve. The CMU analysis program, HTCOEF calculates a mean zero point voltage and a standard deviation of the zero point data (STDZRO). Because the quantity of interest is the uncertainty in the mean zero point, not the individual values, the PNL routine uses the statistical definition of the standard deviation of the mean. (4) The zero point voltage uncertainty can then be described as

$$
\triangle V T C_{0}=2 \times \frac{\text { STDZRO }}{\sqrt{\text { NZERO }}}
$$

Analys is of numerous experimental data runs has indicated that water temperature fluctuations cause a severe disturbance in thermopile voltages. HTCOEF uses the STDZRO value for the uncertainty of arbitrary data points 
$\left(V T C_{x}\right)$ throughout the decay curve. This procedure is not precise because the short window used in the zero point determination does not accurately reflect the water temperature fluctuations over the entire run. (a) Investigation of various data runs has shown that the fluctuation in thermopile voltage is about one tenth of the corresponding fluctuation in water temperature. Then (for a conversion constant of about $5660 \mathrm{mV} /{ }^{\circ} \mathrm{C}$ and root mean square water temperature variation, STDTW) the uncertainty in an arbitrary thermopile voltage point $\left(\Delta V T C_{x}\right)$ can be expressed as

$$
\Delta V T C_{x}=2 \times 1 / 10 \times 5660 \times \text { STDTW }
$$

The total thermopile voltage uncertainty is then

$$
\triangle V T C=\sqrt{\left\{\Delta V T C_{x}\right\}^{2}+\left\{-\Delta V T C_{0}\right\}^{2}}
$$

\subsubsection{Water Temperature}

HTCOEF calculates water temperatures according to the relation

$$
\text { TWATER = THINT + THSLP }(0.001) \mathrm{VTH}
$$

The uncertainty in thermistor voltage (VTH) is composed of two parts, random fluctuating errors and fixed bias errors. The contribution of random errors is evaluated from the actual data. HTCOEF calculates a standard deviation (STDTW) in the NPTAVE water temperature values taken during the analysis window. This quantity is adjusted to reflect the standard deviation in the mean (in the same manner as the mean thermopile voltage) and converted to a voltage quantity

$$
\text { STDVTH }=\frac{\text { STDTW }}{\sqrt{\text { NPTAVE }}} \times \frac{1}{\text { THSLP }(0.001)}
$$

Twice this standard deviation is then added to the estimated thermistor circuit long-term drift (DRFVTH) to obtain the total uncertainty in the thermistor voltages:

$$
\triangle V T H=2 \times \text { STDVTH }+ \text { DRFVTH }
$$

(a) This problem will be discussed more fully in Section 7.1 . 
Adding the effects of the calibration coefficient uncertainties, the final water temperature uncertainty may be expressed as

$$
\Delta T W=\sqrt{\{\Delta T H I\}^{2}+\{(0.001) V T H \times \Delta T H S\}^{2}+\{\text { THSLP }(.001) \Delta V T H\}^{2}}
$$

\subsubsection{Flow Rate}

The volunietric flow rate is calculated from the flowmeter voltage data according to

$$
Q=A V O L F M \sqrt{\frac{V F M-V F M}{\text { VEXCIT } \times \text { FMAMF }}}
$$

where VFM $M_{0}$ VEXCIT, and FMAMP are the flowmeter zero flow voltage, bridge excitation voltage, and amplification factor, respectively. The evaluation of the flowneter voltage uncertainty follows the same procedure used for the thermistor voltages. Because of the quadratic nature of the flow rate equation, the development is somewhat more complicated so only the final expressions wi11 be presented here:

$$
\begin{aligned}
& \text { STDVFM }=\frac{2 \times \text { AVEFV } \times \text { STDFV }}{\sqrt{\text { NPTAVE }}} \times \frac{1}{\text { ALINFM }^{2}} \\
& \text { where } \\
& \text { AVEFV - average flow velocity } \\
& \text { STDFV - standard deviation of the INPTAVE fTow rate } \\
& \text { values taken during the analysis window } \\
& \text { ALINFM - flowmeter calibration coefficient (AVOLFM) } \\
& \text { converted to velocity terms. } \\
& \triangle V F M=2 \times \text { STDVFM }+ \text { DRFVFM }
\end{aligned}
$$


Uncertainties in the measured values of VFM, VEXCIT, and FMAMP are negligible relative to the other terms in the flow rate equation. The overall flow rate uncertainty is then

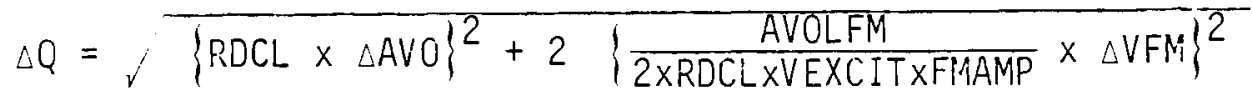

$$
\begin{aligned}
& \text { RDCL }=\frac{\sqrt{\text { VFM - VFM }}}{\text { VEXCITXFMAMP }}
\end{aligned}
$$

To convert flow rate and flow rate uncertainties to velocity terms,

$$
\begin{gathered}
F V=\frac{0.4085}{\text { TUBE } 1 D^{2}} \times Q \\
\Delta F V=\sqrt{\left.\frac{0.4085}{\text { TUBE1D }} \Delta Q\right\}^{2}}
\end{gathered}
$$

At this point subroutine ERROR has completed the uncertainty analysis of the three major data inputs. The task remaining is to determine how these intermediate uncertainties affect the time constant and conductance coefficient.

\section{E.3.4 Time Constant}

The subroutine LINFIT in HTCOEF calculates an uncertainty (SIGMAB) in the thermopile decay slope (B) which is directly proportional to the standard deviation of the thermopile zero point (STDZRO). For the PNL uncertainty analysis it is necessary to reevaluate the uncertainty in the slope based on the revised thermopile voltage uncertainty, $\triangle V T C$. Because of the direct proportionality this is easily accomplished by

$$
\triangle B=(\triangle V T C / S T D Z R O) S I G M A B
$$

Since the time constant is equal to the inverse of the slope, its uncertainty can be expressed as

$$
\triangle T A U=\sqrt{\left\{\frac{\Delta B}{B}\right\}^{2}}
$$




\subsubsection{Conductance Coefficient}

The next step in the data reduction procedure is to calculate a heat transfer conductance from the measured time constant and curve fit coefficients from HTAU:

$$
H_{1}=\exp \left[a+b(x n T A U)+c(2 n T A U)^{2}+d(2 n T A U)^{3}\right]
$$

Following the discussion in Section 5.2, all of the uncertainty in the curve fitting routine will be assigned to the parameter $\triangle F I T$ and the total uncertainty will be

$$
\begin{aligned}
\Delta H_{1} \cdot \sqrt{\exp \left[a+b(\operatorname{lnTAU})+c(\operatorname{lnTAU})^{2}+d(\operatorname{lnTAU})^{3}\right] \cdot\left[b+2 c(\ln T A U)+3 d(\ln T A U)^{2}\right] \cdot} & -(1 / T A U) \Delta T A U\}^{2}+\{\Delta F I T\}^{2}
\end{aligned}
$$

\subsubsection{Air Side Heat Loss Correction}

Correction for $H$ due to air side heat loss is accomplished by

$$
H_{2}=H_{1}\left(1-R_{a i r}\right)
$$

For ERAIR as described in Section 5.2,

$$
\begin{aligned}
& \Delta R_{\text {air }}=\text { ERAIR } \times R_{\text {air }} \\
& \Delta H_{2}=\sqrt{\left\{\left(1-R_{a i r}\right) \Delta H_{7}\right\}^{2}+\left\{\left(-H_{7}\right) \Delta R_{a i r}\right\}^{2}}
\end{aligned}
$$

\subsubsection{Tube Wall Heat Loss Correction}

The tube wall correction is handled in the same manner:

$$
\begin{aligned}
& H_{3}=H_{2}\left(1-R_{\text {walTs }}\right) \\
& \Delta R_{\text {wa17s }}=\text { ERWLS } \times R_{\text {walTs }} \\
& \Delta H_{3}=\sqrt{\left\{\left(1-R_{\text {wa } 115}\right) \Delta H_{2}\right\}^{2}+\left\{\left(-H_{2}\right) \Delta R_{\text {wa } 17 s}\right\}^{2}}
\end{aligned}
$$




\subsubsection{Temperature Normalization}

The temperature normalization of the conductance coefficient to $70^{\circ} \mathrm{F}$ is accomplished by the equation

$$
H_{4}=H_{3}\left[\frac{1+0.012(70)}{1+0.012(T)}\right]
$$

Because the water temperature has been calculated on the Centigrade scale and the normalization equation is in Fahrenheit units a conversion must be made:

$$
\begin{aligned}
& T_{\text {Far }}+1.8 \text { TWATER }+32 \\
& \Delta T_{\text {Far }}=1.8 \times \Delta T_{W}
\end{aligned}
$$

The uncertainty in the normalization procedure has been assigned to the variable ERNOR, as described in Section 5.2 so the overall uncertainty can be calculated from

$$
\begin{aligned}
& \triangle N O R=E R N O R \times H_{4} \\
& \Delta H_{4}=\sqrt{\left\{\left[\frac{1+0.012(70)}{1+0.012\left(T_{F a r}\right)}\right] \Delta H_{3}\right\}^{2}} \\
& +\overline{\left\{H_{3} \frac{[1+0.012(70)](.012)}{\left[1+0.012\left(T_{F a r}\right)\right]^{2}} \Delta T_{F a r}\right\}^{2}+\{\Delta N O R\}^{2}}
\end{aligned}
$$

\subsubsection{Velocity Normalization}

The final step is to nomalize the heat transfer conductance for the unit's nominal velocity, $V_{\text {nom. }}$. This is done by the equation

$$
\frac{1}{\mathrm{H}_{5}}=\frac{1}{\mathrm{H}_{4}}-\text { HRSLPE }\left(\frac{1}{\mathrm{FV}^{0.8}}-\frac{1}{V_{\text {nom }}^{0.8}}\right)
$$

The uncertainty calculation is accomplished in two steps:

$$
\Delta \frac{1}{\mathrm{H}_{5}}=\sqrt{\left.\frac{1}{\mathrm{H}_{4}^{2}} \Delta \mathrm{H}_{4}\right\}^{2}+\left\{\left(\frac{1}{\mathrm{FV}^{0.8}}-\frac{1}{V_{\text {nom }}^{0.8}}\right) \Delta H R S\right\}^{2}+\left\{\frac{\operatorname{HRSLPE}(0.8)}{\mathrm{FV}^{1.8}} \Delta \mathrm{FV}^{\prime 2}\right.}
$$


and

$$
\Delta H_{5}=\sqrt{\left\{H_{5}^{2}\left(\Delta \frac{1}{H_{5}}\right)\right\}^{2}}
$$

The PNL uncertainty analysis for a single data run is now complete. This procedure is repeated for each run in a data set and an average conductance coefficient is calculated according to a weighted averaging process,

$$
H_{a v g}=\frac{\sum \frac{H}{(\Delta H)^{2}}}{\sum \frac{1}{(\Delta H)^{2}}}
$$

This calculation is accomplished in the subroutine ERRES.

A listing of the two subroutines (ERROR and ERRES) containing the PNL uncertainty analysis, and the CMU data reduction code as it was modified to include them, appears in Appendix $A$. 


\subsection{RESULTS}

The PNL uncertainty routine was used to analyze 15 data sets, five each from the Keahole Point, Hawaii; St. Croix, Virgin Islands; and Gulf of Mexico tugboat operations. Final results for these cases appear in Appendix $B$ with the range of values calculated for each data set summarized in Table 1 .

TABLE 1. Conductance Coefficient and Conductance Coefficient Uncertainty Variation

\begin{tabular}{|c|c|c|}
\hline $\begin{array}{l}\text { Data Set } \\
\text { Description } \\
\end{array}$ & $\begin{array}{c}\mathrm{H} \\
\text { Btu/hr-ft2-o } \mathrm{F}\end{array}$ & $\begin{array}{r}\Delta H / H \\
(\%) \\
\end{array}$ \\
\hline ahole Point & & \\
\hline $\begin{array}{l}3 / 23 / 77 \text { - Unit } A \\
3 / 30 / 77 \text { - Unit } A \\
5 / 02 / 77 \text { - Unit } B \\
3 / 08 / 77 \text { - Unit } C \\
3 / 16 / 77 \text { - Unit } C\end{array}$ & $\begin{array}{r}1019 \text { to } 1063 \\
977 \text { to } 1006 \\
523 \text { to } 549 \\
1116 \text { to } 1130 \\
1105 \text { to } 1149\end{array}$ & $\begin{array}{l} \pm 1.9 \text { to } \pm 5.2 \\
\pm 1.9 \text { to } \pm 2.0 \\
\pm 1.3 \text { to } \pm 2.8 \\
\pm 1.1 \text { to } \pm 1.4 \\
\pm 1.1 \text { to } \pm 2.1\end{array}$ \\
\hline
\end{tabular}

St. Croix

$\begin{array}{lll}7 / 24 / 77 \text { - Unit } 1 & 1093 \text { to } 1146 & \pm 2.8 \text { to } \pm 5.9 \\ 7 / 30 / 77 \text { - Unit } 1 & 1011 \text { to } 1179 & \pm 2.9 \text { to } \pm 7.5 \\ 8 / 05 / 77 \text { - Unit } 1 & 1070 \text { to } 1158 & \pm 2.9 \text { to } \pm 6.8 \\ 8 / 17 / 77 \text { - Unit } 1 & 1026 \text { to } 1191 & \pm 2.1 \text { to } \pm 48.5 \\ 9 / 26 / 77 \text { - Unit } 1 & 845 \text { to } 883 & \pm 1.4 \text { to } \pm 4.0\end{array}$

Gulf of Mexico

$\begin{array}{lll}11 / 14 / 77 \text { - Unit 1 } & 847 \text { to } 928 & \pm 4.7 \text { to } \pm 8.2 \\ 11 / 20 / 77 \text { - Unit 1 } & 997 \text { to } 1904 & \pm 7.9 \text { to } \pm 59.7 \\ 11 / 21 / 77 \text { - Unit 2 } & 505 \text { to } 558 & \pm 5.9 \text { to } \pm 10.6 \\ 12 / 05 / 77 \text { - Unit 2 } & 445 \text { to } 740 & \pm 9.6 \text { to } \pm 26.2 \\ 12 / 08 / 77 \text { - Unit 2 } & 471 \text { to } 625 & \pm 7.8 \text { to } \pm 18.4\end{array}$

The results indicate that the conductance coefficient uncertainties for individual runs often varied considerably during the course of an experiment. Figure 2 demonstrates the extent of this variation by showing the frequency distribution of estimated uncertainties for each operation. 

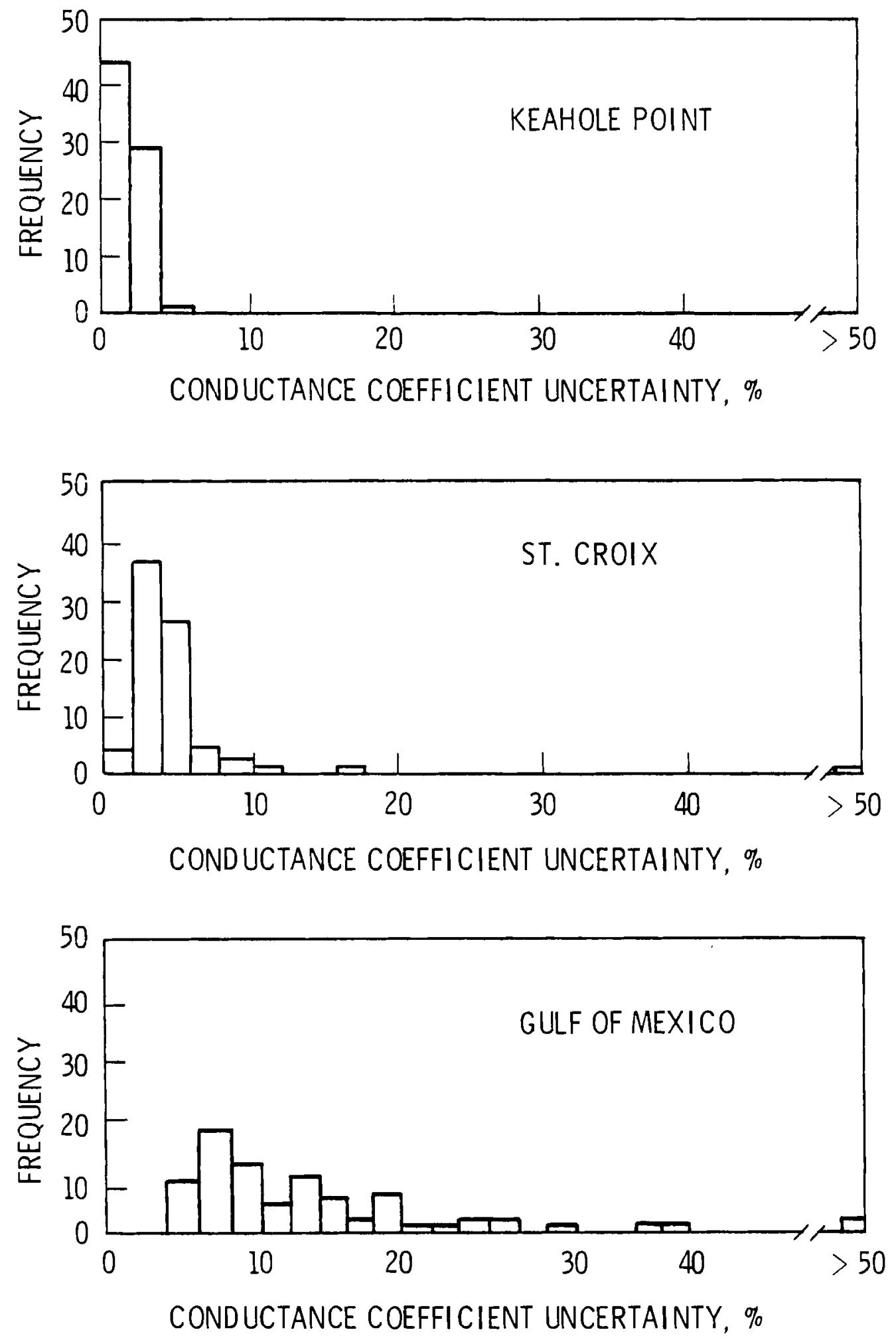

FIGURE 2. Frequency Distribution of Conductance Coefficient Uncertainties 
The CMU data reduction code and PNL uncertainty routine calculate conductance coefficients and conductance coefficient uncertainties. However, the CMU device is routinely used to determine biofouling and corrosion rates over long periods of time. In this application a derivative quantity, the fouling factor, is significant. This parameter is equal to the thermal resistance of the deposited biofouling layer and can be calculated from

$$
R_{f}=\frac{1}{\bar{H}}-\frac{1}{H_{0}}
$$

In this equation $\bar{H}$ is the calculated mean conductance coefficient for a data set and $\mathrm{H}_{0}$ is the calculated mean conductance coefficient for the first data set of an experiment, representing the heat transfer characteristics of the tube for "clean" conditions.

It would be informative to use the conductance coefficient uncertainties predicted by the PNL code to estimate the uncertainties which could be expected when determining fouling factor values. However, a fouling factor is calculated based on the mean conductance coefficient for a data set and the PNL routine does not predict uncertainties for the mean coefficient. (a) While PNL is not aware of a valid technique for assigning an uncertainty to the mean conductance coefficient, an attempt has been made to determine an average uncertainty which could be considered representative for each data set. (b) These values and the corresponding estinated fouling factor uncertainties appear in Table 2.

(a) The reasons for this will be discussed in Section 7.3.

(b) The representative conductance coefficient uncertainty was obtained in the following manner:

$$
\Delta H^{\prime}=\frac{\sum \Delta H}{n}+1.645 \sqrt{\frac{\sum(H-\bar{H})^{2}}{n-1}}
$$

This relationship estimates a value which could be expected to be greater than or equal to $95 \%$ of the individual run conductance coefficient uncertainties if the runs in a data set were repeated without bound under similar operating conditions. It should be emphasized that this quantity is intended as a representative value of the uncertainties calculated for a data set and not as an uncertainty in the mean conductance coefficient. 
It should be noted that it is not possible to calculate a fouling factor or fouling factor uncertainty from one data set. Therefore, the fouling factors presented in Table 2 are based on additional data (a) from the three biofouling experiments. The representative fouling factor uncertainties were estimated by assuming equivalent uncertainties for the corresponding clean tube average conductance coefficients. Also, it should be realized that because of the definition of thermal resistance, only positive values of the fouling factor are meaningful. The negative values appearing in Table 2 are a result of excessive data scatter and should not be regarded rigorously.

\section{TABLE 2. Representative Conductance Coefficient} and Fouling Factor Uncertainties

Data Set Description Keahole Point 3/23/77-Unit $A$ $3 / 30 / 77-\operatorname{lnit} A$ $5 / 02 / 77-$ Unit $B$ 3/08/77-Unit $C$ 3/16/77-Unit $C$

St. Croix

7/24/77-Unit 1 7/30/77-Unit 1 8/05/77-Unit 1 8/17/77-Unit 1 9/26/77-Unit 1

Gulf of Mexico
$11 / 14 / 77-$ Unit 1 $11 / 20 / 77$-Unit 1 $11 / 21 / 77-$ Unit 2 12/05/77-Unit 2 $12 / 08 / 77-$ Unit 2 \begin{tabular}{cc}
$\bar{H}$ & $\Delta H^{\prime}$ \\
Btu/hr-ft2- ${ }^{\circ} F$ & Btu/hr-ft $-{ }^{\circ} \mathrm{F}$ \\
\hline
\end{tabular}

$$
\begin{aligned}
& \pm 41 \\
& \pm \quad 19 \\
& \pm 12 \\
& \pm 15 \\
& \pm 21
\end{aligned}
$$

1028

980

538

1119

1117

1116

1109

1108

1149

867

$$
\begin{array}{r} 
\pm \quad 79 \\
\pm \quad 79 \\
\pm \quad 65 \\
\pm 299 \\
\pm \quad 33
\end{array}
$$

881

1091

529

485

502

73
823
54
164
100

73

823

54

100
0.00009
0.00014
0.00039
0.00003
0.00003

$\pm 0.00005$

$\pm 0.00003$

$\pm 0.00006$

$\pm 0.00002$

$\pm 0.00002$
$\underline{\operatorname{Rr}-f t 2^{\circ}-{ }^{\circ} \mathrm{F} / \mathrm{Btu}} \underline{\mathrm{hr}-f t^{2}-^{\circ} \mathrm{R} / \mathrm{Btu}}$

$\begin{array}{ll}0.00004 & \pm 0.00009 \\ 0.00005 & \pm 0.00009 \\ 0.00005 & \pm 0.00008 \\ 0.00002 & \pm 0.00032 \\ 0.00030 & \pm 0.00006\end{array}$

0.00030

0.00001

$-0.00021$

$-0.00018$

$-0.00001$

$-0.00007$ $\pm 0.00013$

$\pm 0.00098$

$\pm 0.00027$

$\pm 0.00099$

$\pm 0.00056$

(a) Specifically, first day "clean" tube average conductance coefficient results. 


\subsection{DATA REDUCTION AND UNCERTAINTY ANALYSIS PROCEDURE LIMITATIONS}

Under favorable operating conditions, the Carnegie-Melion University biofouling apparatus and data reduction routine represents a precise technique for determining the heat transfer properties in proposed OTEC heat exchanger tubes. The PNL uncertainty analysis subroutine provides rational estimates of the measurement and computational uncertainties. However, certain limiting considerations affecting both of these procedures should be recognized.

\subsection{WATER TEMPERATURE FLUCTUATIONS}

Abrupt fluctuations in the ambient seawater temperature represented a major source of uncertainty in the Hawai i results. The problem is caused jointly by nonideal operating conditions and basic system design. It occurs because of nonidentical thermal time constants in the apparatus reference and heater cylinders. This "tuning" problem causes ambient water temperature fluctuations during a data run to noticeably alter the thermopile voltage output. Analysis of sample data runs indicates that a $0.1{ }^{\circ} \mathrm{C}$ variation in water temperature causes a 60 to $70-\mathrm{mV}$ deviation in thermopile output. Figure 3 illustrates this effect for one sample run from the Keahole Point, Hawaii unit.

The tuning problem affects the thermopile output during the entire decay curve but it is especially troublesome at the end of the decay for two reasons. First, the voltage outputs at the end of a run are much smaller and a constant voltage deviation represents a significantly greater percentage error. Second, the points near the end are used to establish the zero point for adjusting all of the thermopile voltage data, so the effect of any deviation is doubled. The magnitude of this consideration can be seen by looking at the zero points for a sample data set. For the 16 runs from the May 2, 1977 Keahole Point data, the zero point varied from 145 to $239 \mathrm{mV}$ for a range of $94 \mathrm{mV}$. Theoretical analysis of the system components indicated that the random variation from electronic sources should have been only $5 \mathrm{mV}$. 


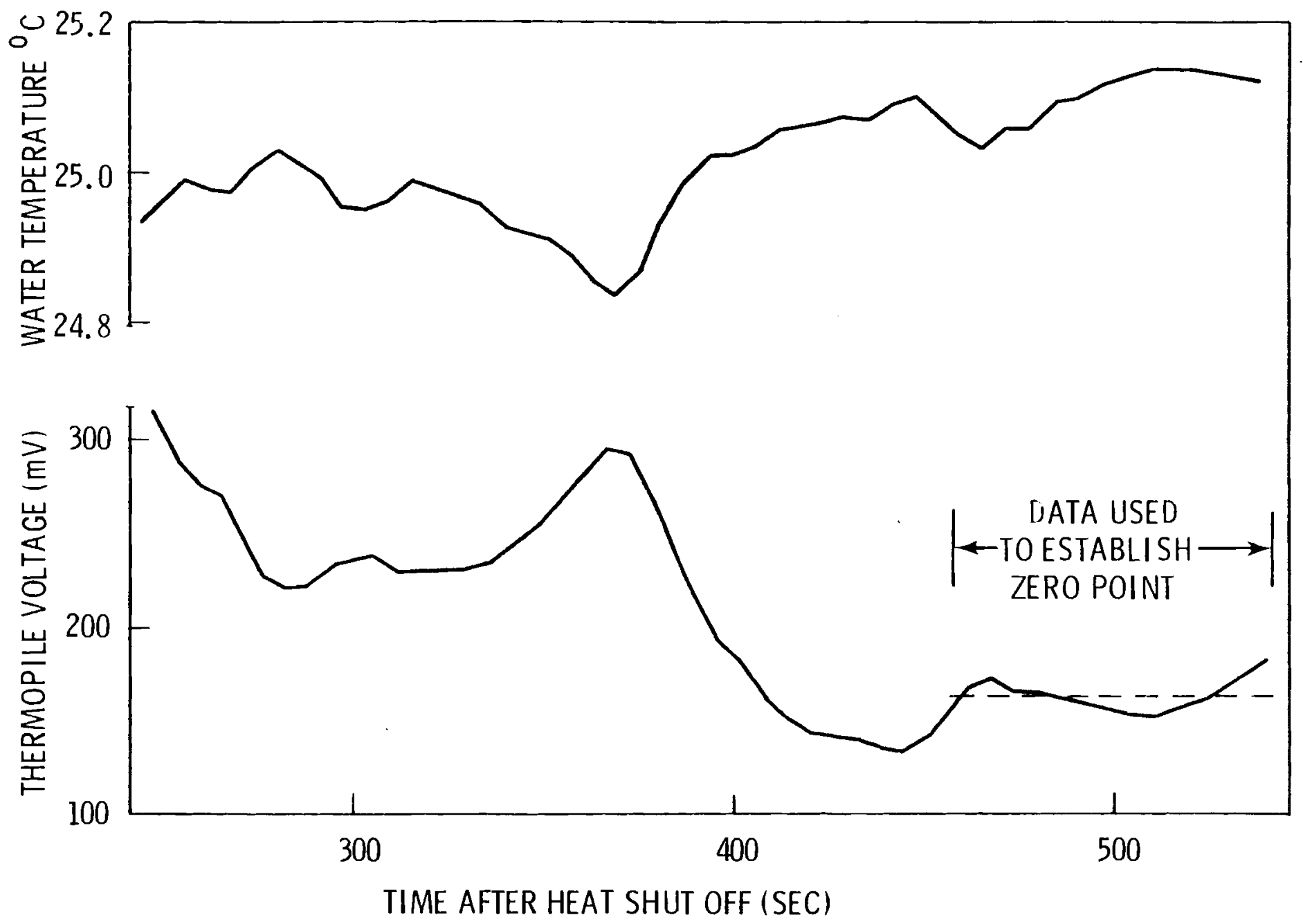

FIGURE 3. Effect of Water Temperature Fluctuations on The rmopile Output (Data from Keahole Point, May 2, 1977, Unit 2, Run 10) 
This problem presents difficulties, not only in establishing an appropriate mean thermopile zero-point, but also in estimating the uncertainty of the thermopile voltage data. As mentioned in Subsection 5.3.1, the CMU data reduction code HTCOEF uses the standard deviation (STDZRO) of the values in the asymptotic window as the uncertainty for the thermopile data. Figure 3 shows that this value is not necessarily a realistic estimate for the overall thermopile voltage data variation.

\subsection{FLOW RATE FLUCTUATIONS}

Fluctuations in flow rate also present a source of uncertainty caused by nonideal operating conditions and the failure of the biofouling apparatus to compensate for them. Flow variations caused excessively high uncertainties during portions of the Gulf of Mexico tugboat operation and looms as a potential problem in any surface-based experiment.

Wave action near the surface can cause rapid variations of flow rate in the sample tube. If the flowmeter does not accurately record these fluctuations, it will be impossible to calculate an appropriate average flow rate, and severe errors will arise when the conductance coefficient is velocity normalized. This occurrence is effectively demonstrated by the Gulf of Mexico data set shown in Figure 4. As can be seen, the conductance coefficient results before velocity normalization were quite stable. This fact indicates that the flow rate did not oscillate sufficiently to impair the ability of the device to determine a conductance coefficient with a high precision. Rather, it was the failure of the flowmeter to allow the determination of the correct average flow rate that introduced the significant errors.

\subsection{HTCOEF UNCERTAINTY PREDICTIONS}

When each of the 16 runs from a standard data set has been analyzed, the CMU computer code calculates an average conductance coefficient and an associated error. The method for calculating the error is based on the statistical definition of the uncertainty in the sample mean. It 

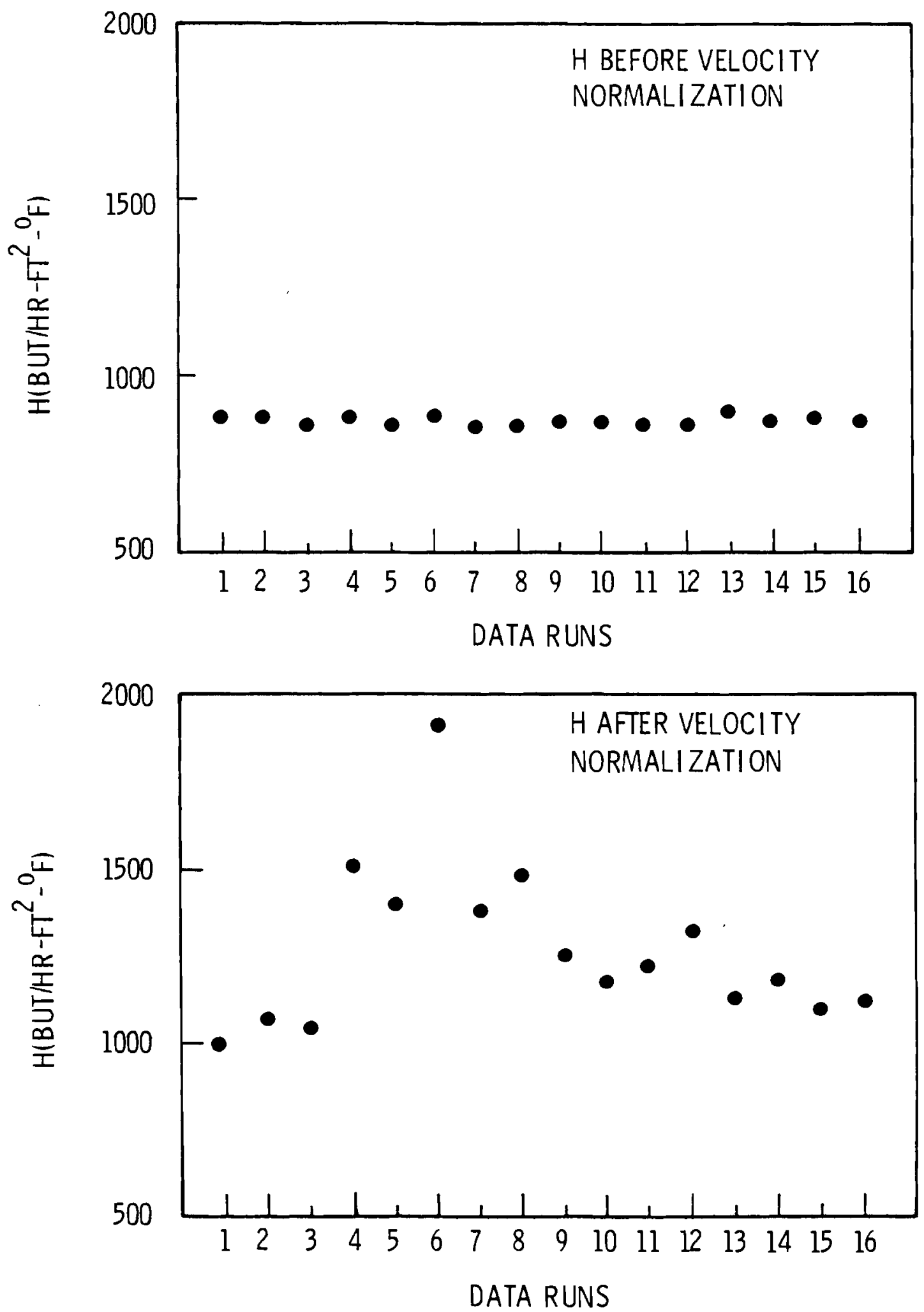

FIGURE 4. Effect of Velocity Normalization on Conductance Coefficients (Data from Gulf of Mexico, November 20, 1977, Unit 1, Runs 1-16) 
yields a value equal to the standard deviation of the individual data points divided by the square root of the number of points taken:

$$
\Delta \bar{H}=\sqrt{\frac{\Sigma_{j}\left(H_{j}-\bar{H}\right)^{2}}{N(N-T)}}
$$

According to this approach, the uncertainty of an experimental device can be reduced without bound by taking a number of readings and averaging the results.

This method is not entirely correct. Taking additional readings will reduce the uncertainty in the calculated mean; however, this value may or may not be the true value of the parent population mean. If only random errors are present in the system and sufficient data points are taken to approach a normal error distribution, the calculated mean will, indeed, approach the true value and the reduced uncertainty will be correct. However, there will always be fixed errors in the apparatus and data reduction procedure which cannot be eliminated by averaging, and the statistical uncertainty in the mean approach will not be valid.

The PNL uncertainty analysis does not utilize this method and, in fact, does not attempt to assign an uncertainty to the data set's average conductance coefficient at a11. Uncertainty estimates are presented for each individual run. They are then used as a weighting factor for the individual data points and a weighted average heat transfer conductance for the group is calculated.

The three 1 imitations just discussed are inherent in the CMU apparatus or computational procedure. Although the PNL uncertainty analysis cannot correct for them, it does estimate the effects of the first two limitations and provides alternative results for the third. The following limitations are of a different nature. They represent factors fundamental to the apparatus design or operation and outside the scope of the PNL uncertainty analysis. 


\subsection{THERMAL ENTRY EFFECTS}

One possible cause of error resulting from a characteristic of the Clil design is thermal boundary layer entrance effects in the copper heater cylinder. Because a thermal boundary layer is developing in the cylinder, the local convective heat transfer coefficient $\left(h_{x}\right)$ changes along the length of the cylinder. Figure 5 shows this behavior qualitatively as a function of axial distance in the cylinder $(x)$ and normalized by the fully developed coefficient $\left(h_{\infty}\right)$.

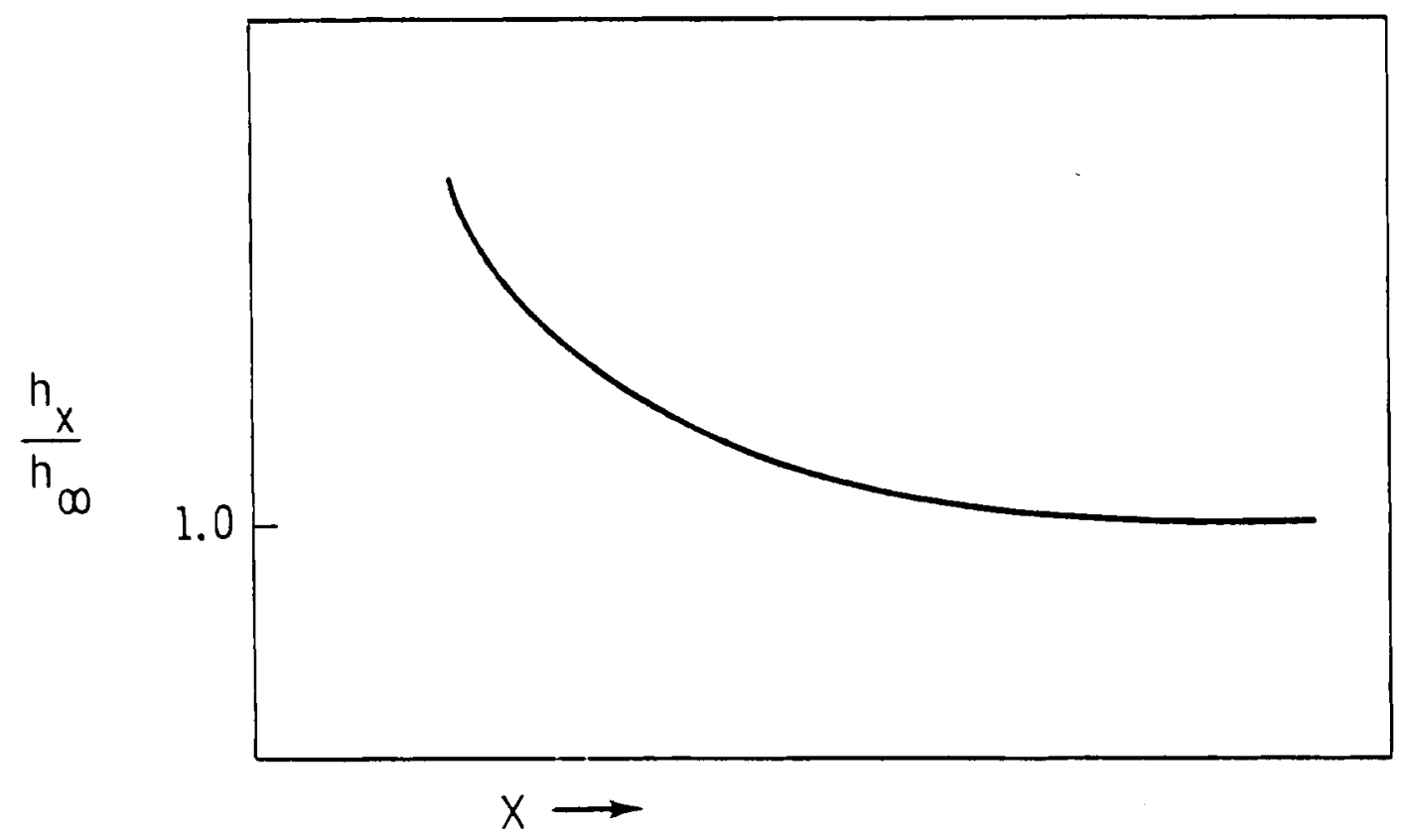

FIGURE 5. Convective Heat Transfer Coefficient in a Thermal Entry Region

At the axial location of the themopile, $h_{x}$ is approximately $10 \%$ higher than $h_{\infty}(6)$ and this ratio will remain constant even as biofouling develops. As a first approximation then, the calculated value of the fouling factor wi11 be approximately 10\% less than the fouling factor for a fully deve1oped boundary 1 ayer. 
Actually, the problem is more complex. The cMu device determines the local value of the overall thermal conductance between the sample tube and the seawater flowing through it. The local $\left(\mathrm{H}_{x}\right)$ and fully developed $\left(H_{\infty}\right)$ values of the combined conductance can be expressed as

$$
\begin{aligned}
& H_{x}=\frac{1}{\frac{1}{h_{x}}+R_{f}} \\
& H_{\infty}=\frac{1}{\frac{1}{h_{\infty}}+k_{f}}
\end{aligned}
$$

and the ratio of these two quantities as

$$
\frac{H_{x}}{H_{\infty}}=\frac{h_{x}}{h_{\infty}}\left(\frac{1+h_{\infty} R_{f}}{1+h_{x} R_{f}}\right)
$$

Because $h_{x} / h_{\infty}$ is constant with respect to time for a given axial location, the ratio of $H_{x} / H_{\infty}$ will decrease as biofouling accumulates. This behavior is illustrated in Figure 6.

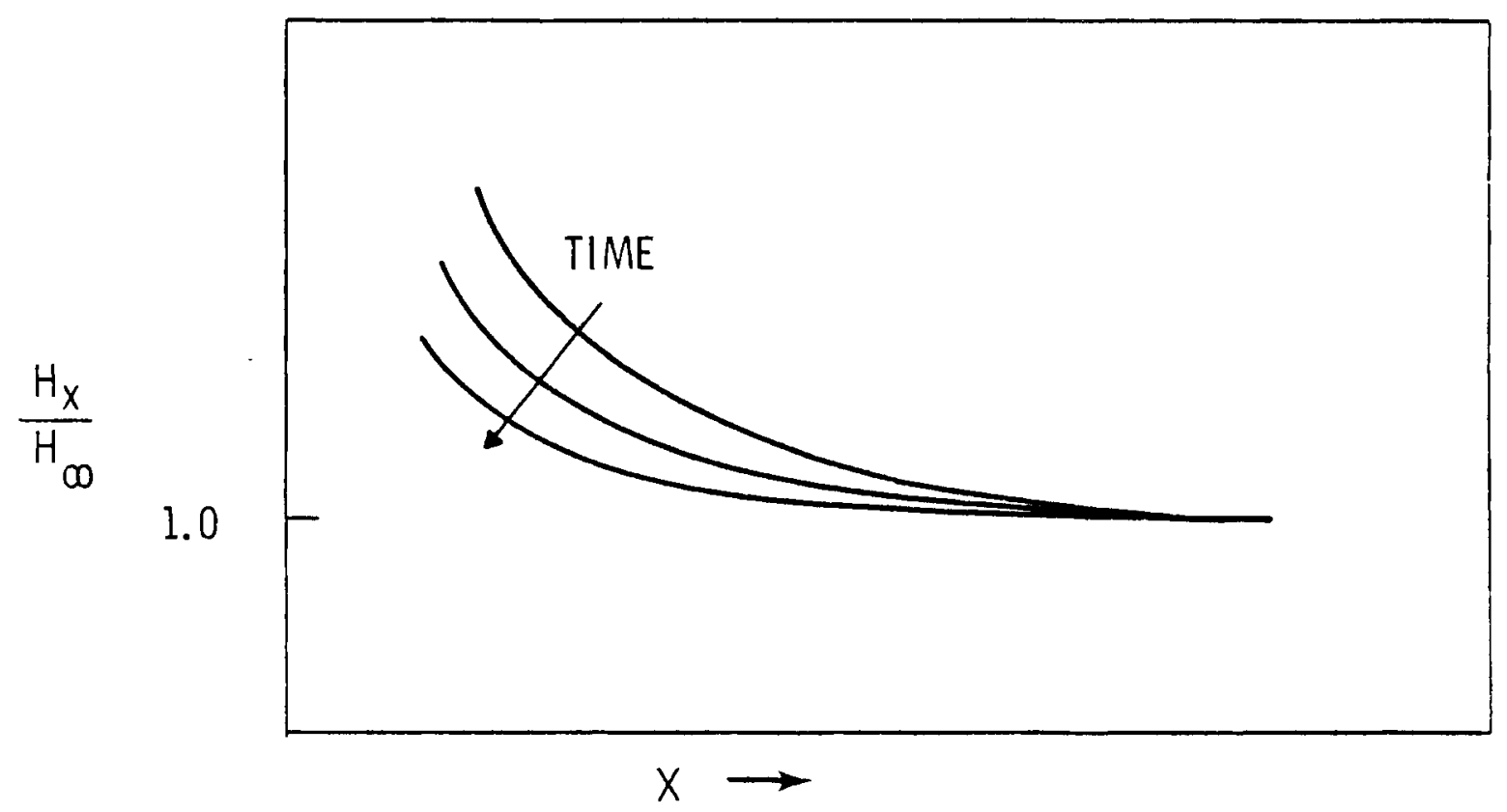

FIGURE 6. Overall Conductance Coefficient in a Therma 1 Entry Region as a Function of Timie 
Therefore, as a test progresses, the local conductance determined by the CMU device and the fully developed conductance, which is the quantity of interest, will both change due to biofouling but they will not change at the same rate.

In summary, the location of the thermopile in an entry region will cause the calculated fouling factor to be consistently lower than the true value. Further, the amount by which the calculated fouling factor differs from the true value will change as a function of time. Because both the CMU data reduction code and PNL uncertainty analysis analyze a group of data from one data set only, it is not possible to correct for this effect or estimate its uncertainty in either code.

\subsection{APPARATUS FAILURES}

At least three other possible design-related failures fall outside the scope of both the CMU and PNL codes. Repeated heating and cooling of the copper heater cylinder or other mechanical deviations could cause the cylinder-to-tube contact resistance to change. This variation would show up directly in the calculated heat transfer conductance. Biofouling or corrosion of the flowmeter element would affect the accuracy of the flow rate measurement. Although this would only indirectly affect the conductance coefficient in the velocity normalization procedure, it could still significantly influence the results. Finally, under current operating procedures it is not possible to monitor the flowmeter circuit electronic drift by recording zero-flow voltage readings on a regular basis. The PNL uncertainty routine includes the estimated effect of longterm drift under normal conditions but cannot account for serious malfunctions.

\subsection{DESIGN IMPROVEMENTS}

Under the proper conditions, the CMU biofouling device and data reduction code, coupled with the PNL uncertainty analysis, provide a highly accurate method for determining the thermal resistance coefficients of biological fouling and estimating their uncertainty. However, the 
limitations presented in this section suggest certain aspects of the design which might represent potential areas for improvement.

Two of the limitations discussed concern the configuration of the copper heater and reference cylinders. It might prove beneficial to modify the heater cylinder so that the overall conductance coefficient could be measured at a location with a fully developed thermal boundary layer. Also, it would be desirable to minimize the water temperature fluctuation problem by matching the thermal time constants of the two cylinders. Making the cylinders more the same size and using identical installation procedures for the thermopile junctions in each cylinder would help achieve this aim.

The flow measurement procedure resulted in at least three limitations. An alternative flowmeter (or related electronics circuit) might reduce the excessive random fluctuation of the flowmeter voltage signal that can be induced by rapid water flow rate fluctuations. It might also make it possible to have fewer mechanical elements in the flow stream and therefore be less susceptible to biofouling and corrosion. Finally, it would be advantageous for the flow measurement procedure to permit regular monitoring of the flowmeter zero-flow voltage without disturbing the hydrodynamic conditions.

It is difficult to suggest a design improvement that would eliminate the uncertainty associated with the cylinder-to-tube contact resistance. Therefore, PNL recommends convective coefficient versus velocity testing (Wilson plots) for each experimental unit at the start and conclusion of a biofouling experiment. These data can be extrapolated to estimate the contact resistance and would reveal any variation during the course of an experiment.

Each of the suggestions discussed here was an inherent result of the uncertainty analysis conducted at PNL and does not reflect an extensive examination of the CML biofouling measurement device. They are intended as considerations which should be investigated more fully in the aim of effecting meaningful improvements in the biofouling device. 


\section{-}




\section{REFERENCES}

1. E. C. Haderlie, The Nature of Primary Organic Films in the Marine Environment and Their Significance for Ocean Thermal Energy Conversion (OTEC) Heat Exchange Surfaces. NPS-68 HC 77021, Naval Postgraduate Schoo 1, Monterey, CA, 1977.

2. J. G. Fetkovich, G. N. Granneman, L. M. Mahalingam, D. L. Meier, and F. C. Munchmeyer, "Studies of Biofouling in Ocean Thermal Energy Conversion Plants." Presented to the Spring Meeting/STAR Symposium of the Society of Naval Architects and Marine Engineers, San Francisco, CA, 1977.

3. J. G. Fetkovich, G. N. Granneman, D. L. Meier, and F. C. Munchmeyer, Progress Report - Fouling and Corrosion Studies in OTEC-Related Heat Exchanger Tubes. National Technical Information Service, Springfield, VA $22151,1976$.

4. P. R. Bevington, Data Reduction and Error Analysis for the Physical Sciences. McGraw-Hill, New York, NY, 1969.

5. F. Kreith, Principles of Heat Transfer. Intext Educational Publishers, New York, NY, p. 395, 1973.

6. W. M. Kays, Convective Heat and Mass Transfer. McGraw-Hi11, New York, NY, 1966. 


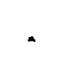


APPENDIX A

CMU DATA REDUCTION CODE AND PNL UNCERTAINTY ANALYSIS ROUTINE 


\section{APPENDIX A}

CMU DATA REDUCTION CODE AND

PNL UNCERTAINTY ANALYSIS ROUT INE

Appendix A contains a listing of the CMU data reduction code, HTCOEF (p. A-2) with the PNL uncertainty analysis subroutines, ERROR ( $P$. A-20) and ERRES ( $p . A-23)$. No changes were made in the logic of HTCOEF although some of the subroutine cal1 statenents and common specifications were slightly modified in order to accommodate the uncertainty routine. The listing presents the code in the format used to analyze the Keahole Point, Hawai i data on a CDC CYBER 6600 computer. 
PROGRAM HTCOEF (INFUT, OUTPUT, TAPES=INPUT, TAPESEOUTPUT)

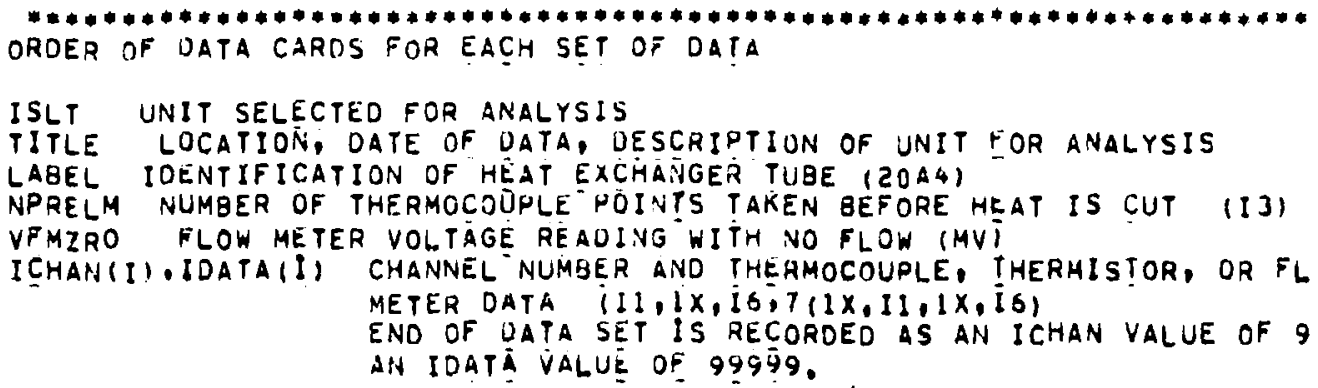

TIMIVL TIME INTERVAL BETWEEN SUCCESSIVE PIECES OF DATA! FOR EXAMPLE THERMOPILE DATA ARE TAKEN ÁT TAO SEC, THERMISTOR DATA AT TEZ 5 ANO FLOH METER OATA AT TEL SEC, THEN TIMIVLD2:O SEC.

NZERO HUMBER OF THERMOPILE DATA POINTS AT THE ENO OF THE OECAY WHICH USED IN CALLULATING THE ZERO POINT FOR THE THERMOPILE AS WELLI ESTIMATING A CONSTANT IN THE WEGGHTINO OF THE DECAY DATA FORT OF TAU.

TMININ TIME PMEASURED AFTER HEAT HAS GEEN CUTI WHICH MARKS THE BEGIN OF THE ANALYSIS WINDOW FOR FITTIÑE TAU.

WINDOW NUMBER OF TIME CONSTANTS AFTER TMININ OURING WHICH THE THEHMO DECAY IS TO BE ANALYZED TO EXTRACI A TAU.

NPCARD NUMBER OF DATA POINTS PER CARD:

RAD3 1/2 OD OF HEATER CYLINOERS (IN).

HAIR CONVECTIVE COEFFICIENT FOR CYLINDER HEAT LOSS TO AIR.

AKCYL THERMAL CONOUCTIVITY OF HEATER CYLINDERS (BTU/HR FT E).

ALENGTH LENOTH OF HEATER CYLINOER SET" (IN).

FMAMP FLOWMETER AMPLIFICATION FÄCTÓR.

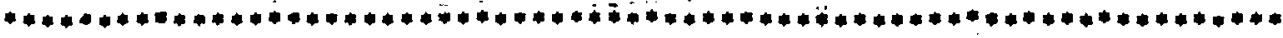

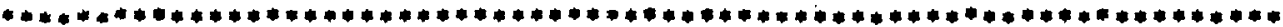
VALUES FOR THE FOLLOWING UNIT DEPENOENT VARIABLES ARE MADE AVAILABLE! IN THE SUHROUTINE LKTBLE

THINT INTERCEPT IN CENTIGRADE DEGGRES OF THE THERMISTTOR CALIBRATION (TWATER(I) = THINT + THSLLP WTHIII)

THSLP SLUPE OF THERMISTOR CALIBRATION CURVE ABOVE.

VEXCIT EXCITATION VOLTAGE IN VOLTS OF FAMAPO FLOW METER STRAIN GAUGE

LVOLFM CALIBRATION CONSTANT OF RAMAPO FLOW METER FOR USE IN CALIBRAT EQUATION FLOW (GALAMIN) = AVOLFH+SORT ( VFM-VFMZROI/VEXSIT)

TUEEID IU OF IHEAT EXCHANGER TUGE (IN):

HINTR INTERCEPI ON OROINATE AXIS IN I/H VERSUS $/ V * 0.8$ PLOT.

ACCN, BCCN, CCCN, DCCN COEFFICIENTS IN THE RELATION WHICH CONVERTS T H ACCOROING TO TWCOCYLIÑOER MOOEL WITH NO AIR, WALL, OR INTE COHRECTIONS. WITH TAU IN SEECONDS AND H IN BTU/HR FT*\#2 F, THE RELATION IS

LN (H) $\because A C C N+B C C N *(L N(T A U))+C C C N *(L N(T A U)) * 2+O C C N *(L N(T A U)) * 3$

RAfJ l I/2 IN OF TUBE IINI.

RADZ $1 / 2$ OD OF TUBE (IN). 


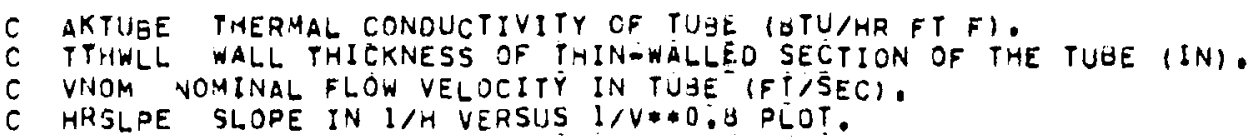

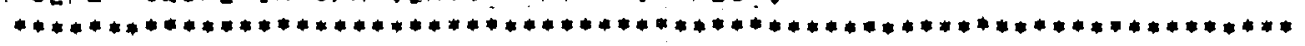

DIMENSION LABEL $(20)$

DIMENSION ICHAN $(3.30)$, IDATA $(330)$, TTC $(110)$, VTC $(110), V T C S M F(110)$

DIMENSION TTH $(110), V T H(110)$, TTHSHF 1110$), V T H S H F(110)$

DIMENSION TFM(110), VFM(I10),TFMSHF (110), VFMSHF (1]U)

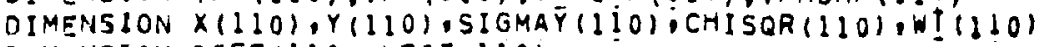

DIMENSION OIFF $(110)$, YFIT $(110)$

DIMENSION TWATER (110), FLOVEL $(110)$

COMYON ICHAN, IOATA, TTC, VTC, VTCSAF, TTHOVTH, TTHSHF, VTHSHE, TFM, VFM,

$\mathrm{C}$ TFMSHF, VFMSHF IX, Y SI I GMY ICHISUR,WT, DIFF, YEITITWATER,FLOVEL COMMON /BLKZI TITLE(20)

COMMON /ALKB/ THINT, THSLP, VEXCIT, AVOLFM, ACCN,BCCN,CCCN,DECN,

C

$\mathrm{C}$ OLTTHI, DLTTHS, ULTTAVO, ULTHRS, OLTFIT

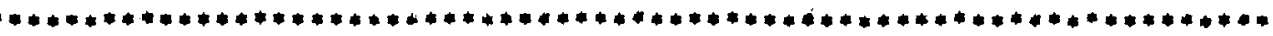




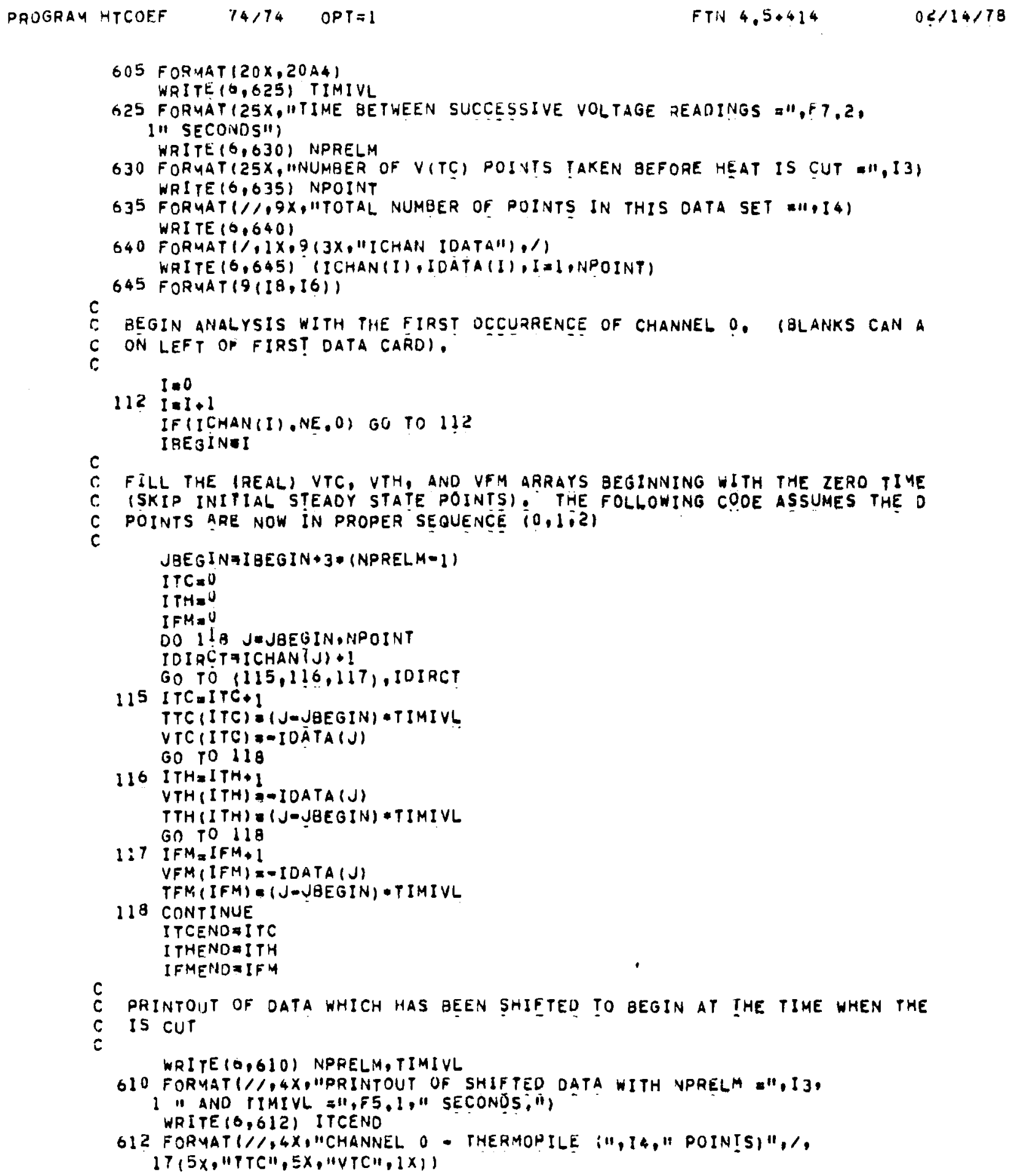




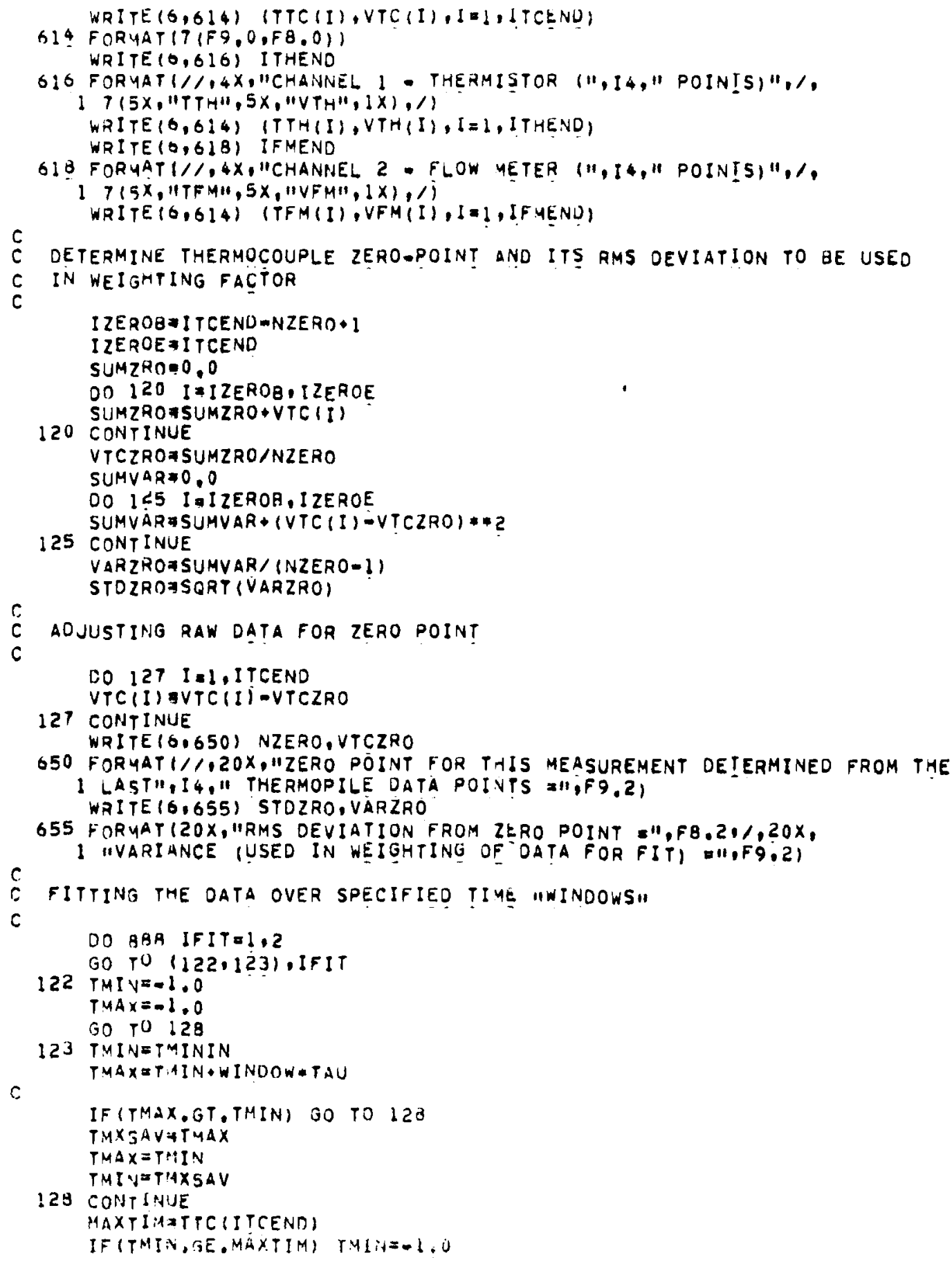


IF (TMIN.GT.0.0) GO TO 130

TMIVI 0.0

LBEGINN!

GO TO 140

130 CONTINUE

DO 135 I 1 I, ITCEND

IF(TMIN.OT,TTCII) GO TO 135

LBEGINEI

GO TO 140

135 CONTINUE

140 CONTINUE

IF (TMAX,GE, MAXTIM) TMAX $=-1.0$

IF(TMAX.GT,0.0) GO TO 145

TMAX =MAXT IM

LEND IT TCEND

NPTF IT IEEND-LBEGIN+

GO rO 150

145 CONTINUE

DO 147 I ILAEGIN, ITCEND

IF (TTCII).L.T.TMAX) GO TO 147

LEND=I-]

NPTFITILEND-LBEGIN+I

GO TO 150

147 CONTINUE

c

150 CONTINUE

C FILLING ARRAY WITH VARIABLESS FROM TIME "WINOOWS"

$c$

OO 155 I 1 , NP.TFIT

$L=L$ AEGLNOI-I

$X(I)=T T C$ (L)

VTCSHF (I) aVTC L

TTHSHF (I) aTTA(L)

VTHSHF (I) $=V T H(L)$

TFMSHF (I) =TFM(L)

VFMSHF(I) VFM(L)

ARG I AQSS(VTC (L))

IF (ARGL .LT.0.001) ARG $1=0.001$

$Y(I)=A L O G(A R G I)$

ARG ZEVTC (L)

IF $(\triangle R G 3, E Q, 0.0)$ ARG3 3.001

SIGNAY(I) \#STOZRO/ARG3

155 CONTINUE

CALL: LINFIT $(X, Y, S I G M A Y, N P T F I T, I, A, S I G M A A, B$, SIGMAB,R,WT, CHISOR,

$I$ CHITOR,STDI

DO 157 I $=$ I. NPTFIT

YFIT $(I)=A \cdot B * \dot{X}(I)$

$\triangle R G ?=\triangle B S(V T C S H F(I))$

IF (AHG2.LT.0.001) ARGZ $=0.001$

DIFF(I)-YFIT II)-ALOG (ARGZ)

c

157 CONTINUE

FITTED VARIABLES AND ERRORS TRANSYFORMED TO VARIABLES OF THE PROBLEM A THEIR ERRURS

$V O=E X P(A)$

VOHI UHEEXP(A.SIGMAA) 
VOLOWIXEXP $(A-S I G M A A)$

$T A U=-1.0 / 3$

TAUHI $=+1.0 /(B+5 I G M A B)$

TAULOWB-1.0/(B-5IGMAB)

WINTAU $=$ (TMAX-TMIN) /TAU

WRITE (6.660) IFIT, ISET

660 FORYATI///,20X,"FIT", [3," FOR DATA SET",I3,/

WRITE $(0,605)$ LABEL

WRITE $(0,665)$

665 FORYATI\%,2OX."FIT OATA (AOJUSTED FOR ZERO POINT) IO STRAIGHT LINE

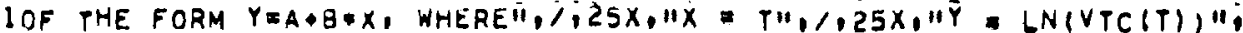

$2 /, 25 X, " A=L N(V(T=0), 11, \%, 25 X, " B=-1 / T A U \|$

WAITE $(6,670)$ NPTFIT, TMIN, TMAX, WINTAU

670 FORMATI/,20X,"ONLY",15," DATA POINTS WHICH SATISFY THE CRITERIA T.

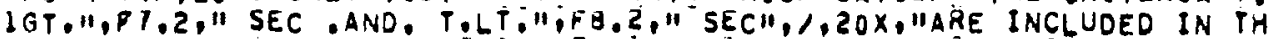
2E FII",/,20X."THIS WINOOW IS"FF6.2,"TIME CONSTANIS WIDE"I WRITE (6.675) A,SIOMAA,B, SIGMAB,CAITOTISTD,R

675 FORMATI/,20X,"RESULT OF THE FITH,/,25X,"A " ,FI0,6,7X, "SIGMAA "

I F $10,7,1,25 x_{1}, B=11, F 10,7,7 x_{0}, " S I G M A B=", F 10,7,1,25 \bar{x}_{1}$

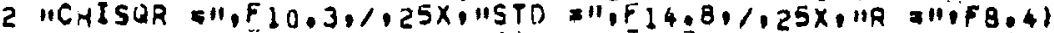
WRITE $(0,680)$ VO, VOLOW, VOHIGH

680 FORYATI/,20X,"IOR, IN TERMS OF VARIAYLES OF THE PROBLEMH, $/ 25 X$,

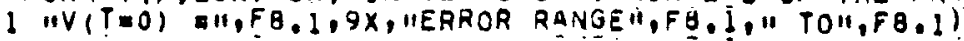

WRITE (6,685) TAU, TAULOW T TAUHI

c

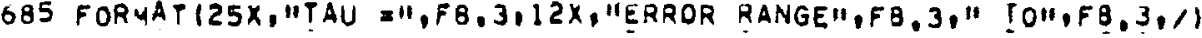

C CONVERTING THERMISTOR SIGNAL TO WATER TEMPERATURE (C) AND

C FLOW METER SIGNAL TO FLOẂ VELOCITY TFTIŚECI.

C

SUMTWNO. O

SUMFV $=0.0$

QTOV $=0.4085 /$ TUBEID*2

ALI VFMAAVOLFMESQRT (, $0 / V E X C I T / F$ YAMP) *QTOV

NPTAVE ENPTFIT-I

DO 160 I I I.NPTAVE

TWATER (I) $=$ THINT THSLP * $(0.00] * V T H S H E(I))$

SUMTW = SUMTW TWATER(I)

FLOVELII) A ALINFM SORT (VFMSHF (I) -VFMZRO)

SUMFV = SUMFV +FLOVEL (I)

160 CONTINUE

AVETWESUMTW/NPTAVE

AVEFVDSUMFVINPTAVE

$c$

STANDARO DEVIATION OF WATER TEMPËRATURE AND FLOW VELOCITY OVER ANALYS WINOOW

SUMSQT $=0.0$

SUMSQF $=0.0$

DO 165 IEL, NPTAVE

SUMSUT FSUMSQT + (TWATER (i) - AVETW) - - ?

SUM SOF = SUMSOF + (FLOVEL (I) \#AVEFV) * ?

165 CONTINIIE

STOTW=SORT (SUMSQT/ (NPTAVE- I))

STOEVASART (SUMSOF/(NPTAVE-1))

WRITE $(0,6$, S6)

686 FOR UATIZUX, "COHVERTED UATA DURIVIS GNALYSIS WINOOW" "I,

LIOX, "TIME (SEC)", 3X."THERMOPILE VOLTAGE", J 3X, "TIME (SEC)", 
PROGRAM HTCOEF $\quad 74 / 74 \quad$ OPT $=1 \quad$ FTN $4.5+414 \quad 0 \leq 114 / 78$

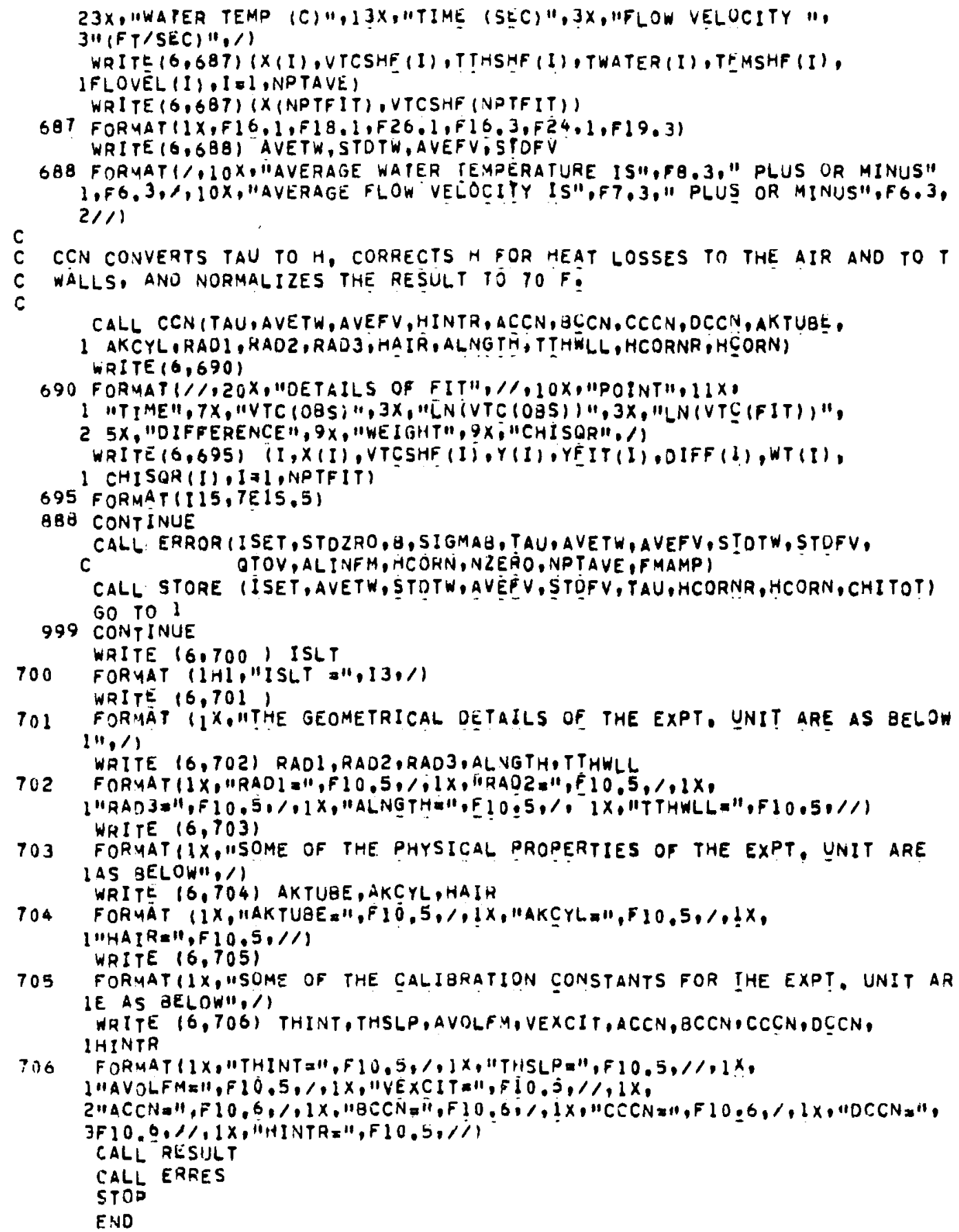


SUBROUTINE LINFITIX,Y,SIGMAY,NPTS, MODE, A, SIGMAA,B, SIGMAB,R,WT,

I CHISQH, CHITOT,STDI

$c$
$c$
$c$
$c$

LINFIT WAS LIFTED FROM "DATA REDUCTION AND ERROR ANALYSIS FUR THE PHY SCIENCES" BY BEVINGTON, PAGE 104

DOUALE PRECISION SUM, SUMX, SUMY, SUMXZ, SUMYZ DOUZLE PRECISION XI, YI, WEIGHT,DELTA V VARNCE

c OIMENSION X(j),Y(1),SIGMAY(I),CHISQR(! ),WT(I)

c

$11 S U M \times 0$ SUMX $\approx 0$. SUMY $=0$. SUMX $\leq=0$. SUMXY=0. SUMYŻO:

21 DO $50 \quad I=1, N P T S$

$X I=x(I)$

$Y I=Y(I)$

IF (MOOE) $31.36,38$

31 I $F(Y) \quad 34,36 ; 32$

32 WEIGHTML, /YI GO TO $\$$

34 WEIGHTEL,/ $(-Y I)$ GO TO 1

36 WEIGHTII. GO TO 1

38 WEIGHTII,/5IGMAY (I)*०2

WT (I) EWEIGHT

41 SUMESUM W WEIGHT

SUMX $\approx$ SUMX * WE I GHT $* X$

SUMY $=5 U M Y * W E I G H T * Y$

SUMX $2=5 U M X Z$ WEIGHT*XI*XI

SUMXY $=5 U M X Y * W E I G H T * X I * Y I$ SUMYZ\#SUMYZ*WEIGHT:YI*YI

c

50 CONTINUE

C CALCULATE COEFFICIENTS AND STANOARD DEVIATIONS

51 DELTAESUM*SUMXZ - SUMX $*$ SUMX

$A=$ (SUMX2* SUMY - SUMX*SUMXY)/UELTA

53 B. (SUMXY.SUM - SUMX*SUMY) IDELTA

CHITOT:0.0

DO 55 I II,NPTS

$C H I S Q R(I)=W T(I) *(A+B * X(I)-Y(I)) * 2$

CHITOTECHITOT * CHISOR(I)

55 CONTINUE

61 IF (MODE) $62,64,62$

62 VARACER I.

GO TO 67

64 C=NPTS-2

VARYCEA ISUMYZ * A*A*SUM * B*H*SUMXZ

$1-2$. (A*SUMY * B*SUMXY $-A * B * 5 U 4 X)) / C$

67 SIGUAAGDSORT (VAFNCE SUMX 2 /OELTA)

68 SIGAAE F SORT (VARNCE - SUHA DELTAI

TI RE (SUM*SUMXY - SUMX* SUMY)

I OSQRT IOELTA*(SUM-SUMYZ - SUMY*SUMY))

STOS (NPTS/ (NPTS-2,)) (CHITOT/SUM)

STD =SORT (STOS)

RETURN

END 
SUBROUTINE CCNITAU, TWATER,FLOVEL,HINTR,A,B, C,D, AK TUBE, 1 AKCYL,RADI, RADZ, RAD , HAIR, ALNGTH, TYHWLL, HCORNR, HCORN) COMYON /RLKA/ VNOM, HRSLPE

COMYON /BLKC/ HUNCOR, FNTAU,RAIR, HCORA,RWALLS,HCOR,HCORNT

TAU IS CONVERTED TO N BY THE RELATION

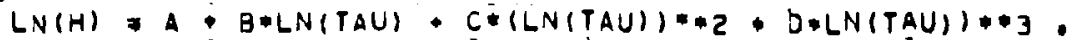
THIS RELATION IS A FIT TO THE NUMBERS THAT WERE GENERATED BY HTAU IFE TWO-CYLINUER PROGRAMI

IF (TAU,LT.0.0001) RETURN

FNTAUU $=A L O G(T A U)$

$F N H=A+B * F N T A U+C * F N T A U *+Z+D * F, V T A U * 3$

HUNCORФEXP (FNH)

HWATRR 3 I. O/HUNCOR-HINTR

CORRECTIONS FOR HEAT LOSS TO AIR ANO TO WALLS OF HEAI

EXCHANGER TUBE. SEE PAGE IIO OR LAB BOOK II,

$H C Y L=(A K C Y L / R A D 1 * 12.0) / A L O G(R A D Z / R A D 2)$

HCYLR=1.0/HCYL

HTUGE = (AKTUBE/RADL 22.0$) / A L O Q$ (RAD2/RAOI)

HTUBEAMI.O/HTUAE

RAIR= $(H C Y L R+H I N T R * H T U B E R+H W A I R R) * H A I R *(R A D 3 / R A O I)$

C

HCORAIHUNCOR $11.0-R A I R$ I

HWTUWRAI.O/HCORA-HINTR

HWTUW=1.0/HWTUWR

WLLCONE $(2,0 / A L N G T H * 12,0)$ SOR T (AKIUEE *TTHWLL/12.0)

RWALLSAWLLCON/SORT (HWTUW)

HCORAW AHWTUW: $(1,0 \rightarrow R W A L L S)$

HCORR = 1. O/HCORAW + HINTR

$H C O R=1.0 / H C O R R$

c

NORMALIZE HCOR IO 70 F BY THE FACTOR (! . .012*TWATER )

ANORM=11.0*.012*70.1/11.0*.012*1!.8*TWATER+32.1)

HCRAWNAANORM HCORAW

HCRNTR I I. O/HCRAWN P HINTR

HCORNT $1.0 /$ HCRNTR

WRITE $(6,600)$

600 FORMAT $/ /, 20 X$, "TIME CONSTANT (TAU) CONVERTED TO HEAT TRANSFER COEF

IFICIEN (H) WITH CORRECTIONS FOR HEÁT LOSS", $/ .20 X$ I

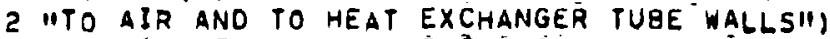

WRITE $(6,605)$ MUNCOR, HINTRIRAIR, RWALLSIHCOR

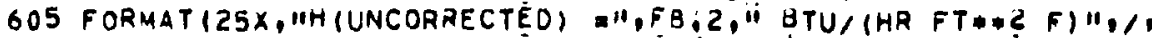

$125 \times, " 1.0 / H I N T E R C E P T=11 ; F 9.6, "$ (BTU/HR FT*2 F)**-11,11

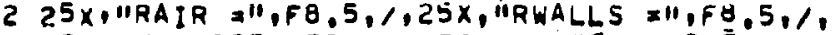

$325 x, \cdots H(C O R R E C T E D)=", F B, 2, " B T U /(H R F T * 2$ F)"1) WAITE $(6,610)$

610 FORMAT $/, 20 X$, WW(CORAECTED) NORMALIZEO TO 70 F (NOHMALIZATION STHIS ITLY NOT CORRECT SINCE THE TEHPEAATURE-INDEPENDENTH./2OX,

2 "FOULING CONTRIEUTION IS NOT SUUTTRACTED FROM H(CORRECTEU)"I) WAITE $(0,625)$ AHORM, HCORNT, HICRNIA

615 FORMAT $125 x$, "NORMALIZATION FACTOA =11,56,3,/,25X,"HICORRECTED,NORMAL

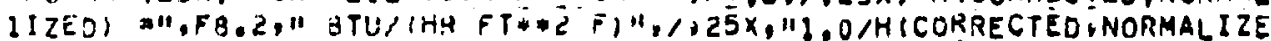
20) $=", 79,7,1$ 
C NORMALISE FOR NOMINAL VELOCITY

VBR: FLOVEL * $(-0,8)$

VNOMUR: VNOM $*(-0,8)$

VELCORA HRSLPE IVBR - VNOMBR,

HCORNR HCRNTR - VELCOR

HCORNA 1., HCORNR

WRITE $(6,616)$ VNOM, HRSLPE

616 FORMAT $1 /, 20 X_{1}$ IINOMINAL VELOCITY =11,FY.3.1,

$120 X$."SLOPE USED FOR VELOCITY NORMALISATION =11, EI2:5.1/1

WRI TE 16,6171 VELCOR, HCORNR, HCORN

617 FORYATTI2OX,"CORRECTION IN I/H DUE TO VELOCITY NORMALISATION W",

$1 E 12.5,1.20 X, " 1 / H$ AFTER VELOCITY NORMALISATION $=11,12.51 \%$

$220 X, " H$ AFTER VELOCITY NORMALISATION=11,F $8,2,111$

RETURN

END 


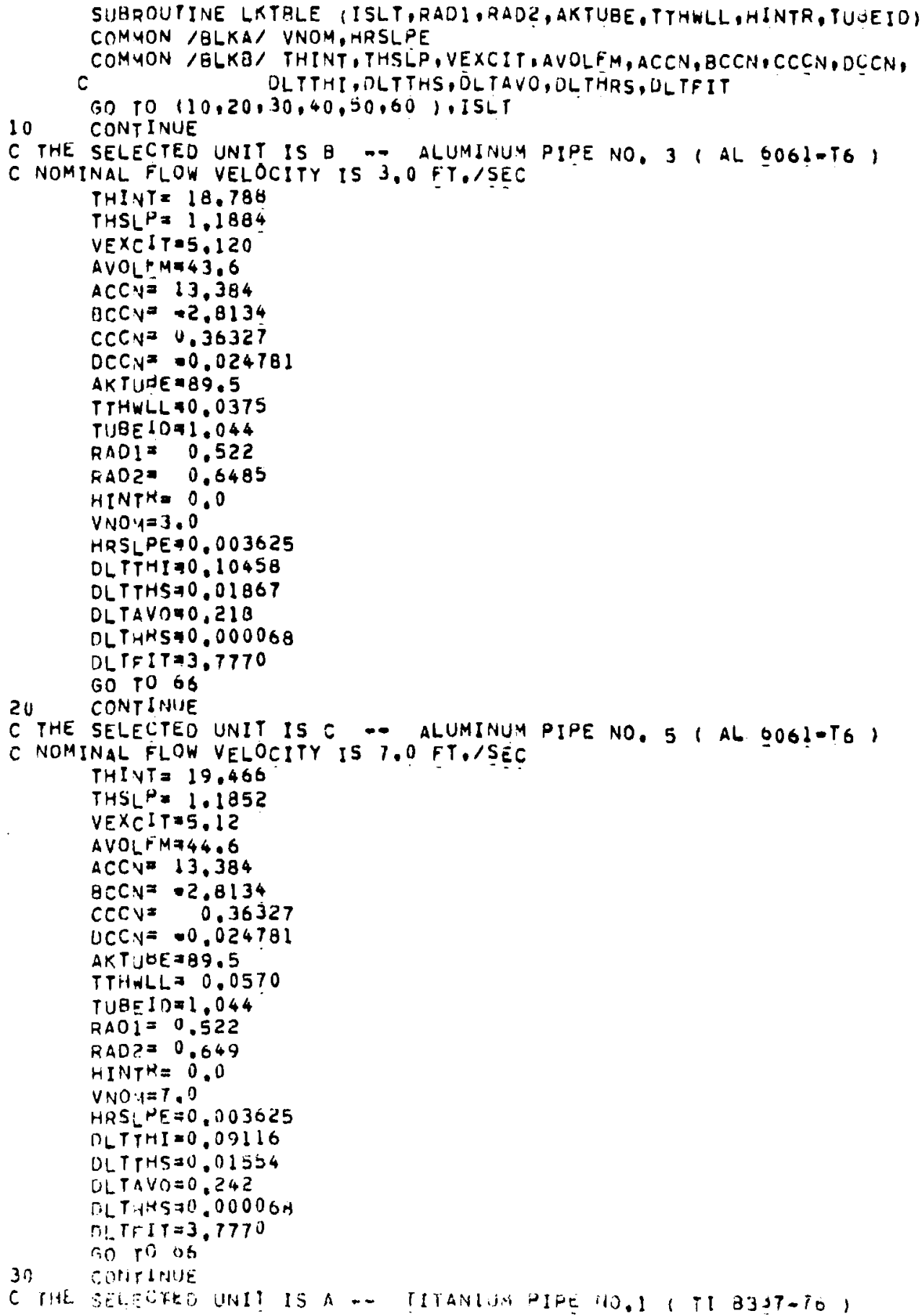


C NOMINAL FLOW VELOCITY IS 6,5 FT./SEC

THIVT= 18.528

THSLP $=1.1917$

VEXCIT $=5.12$

AVOLFMA45.?

$\triangle C C V=36.084$

BCC.N $=-16.276$

$C C C_{N}=3.0628^{\circ}$

DCCN= $=0.20682$

AKTUUE 912.7

TTHWLLAO.122

TUBEIO $\$ 1.055$

RADI $=0.5275$

RAD? $=0.6495$

HINTHE 0.0

VNOM $\approx 6,5$

HRSLPE $=0,003632$

OLTFHI $=0.08228$

OLTTHSA0.01477

DLTAVO=0.0173

DLTHRS=0.000032

DLTFIT 18.6706

GO TO 66

40 CONTINUE

C THE SELECTED UNIT IS FOUR

THIVT=0.0

THSLPEO.0

VEXCIT $=0.0$

$A V O L P M=0.0$

$A C C N=0.0$

$\operatorname{BCC} v=0.0$

CCCY $=0.0$

DCCN $=0.0$

AKTUUE00.0

TTHWLL 00.0

TUOEION0.0

RADI $=0.0$

RADZ $=0.0$

HINTK=0.0

VNOY 0.0

HRS $P E=0.0$

DLTTHI 0.0

DLTTHS 0.0

OLTAVOA0.0

OL THRS $=0.0$

DLTFIT $T=0.0$

GO TO 66

50 CONTINUE

C THE SELECTEO UNIT IS FIVE

$T H I N T=0.0$

THSLP $=0.0$

VEXC\T=0.0

AYOL MaO O O

$A C C N=0.0$

$B C C Y=0.0$

$C C C V=0.0$

DCC $=0.0$ 
AKT UUE $\Rightarrow 0.0$

TTHWLL $=0.0$

TUAE D $0 \Rightarrow 0.0$

$R A D I=0.0$

RADZ $=0.0$

HINTR=0.0

$V N O Y=0,0$

HRSLPEFO.0

DLTTMI $=0.0$

OLTYMSA0.0

OLTAVO 0.0

OLT:ARS $\$ 0.0$

OLTEITA0.0

GO TO 66

60 CONTINUE

C THE SELECTED UNIT IS SIX

$T H I N T=0.0$

THSL $=0.0$

VEXCIT $=0.0$

AVOL $P=0,0$

ACCV $=0.0$

$B C_{N}=0.0$

$\operatorname{CCCN}=0.0$

DCCN $=0.0$

AKT UUE $=0.0$

TTHWLL $\Rightarrow 0.0$

TIJAE I 070.0

$R A D 1=0.0$

RADZ=0.0

HINTH $=0,0$

$\checkmark N O Y=0.0$

HRSL $P E=0.0$

DLTTHIDO.0

DLTTHSM0.0

DLTAVO 40.0

OLTYRS $=0.0$

OLTF $\$ T=0.0$

GO TO 66

66

CONTINUE

RETURN

END

FTN $4.5+414$

$0 \div / 14 / 78$

SUBROUTINE STORE, ISET,AVETW,STOTW.AVEFV, STOFY,TAU, HCORNR, IHCORN, CHITOT I

DIMENSION IRUN(25), TW(25), OELIW(25), VW(25, OELVW(25),CHISO(25)

DIMENSION TCON(25), H(25), HR(25)

COMMON /BLKE/ IRUN, TW,DELTW,VW, OELVW, CHISO, TCON,HOHR

COMMON

$i=\{$ SET

[RUIN $\{$ I I) $=$ ISET

TW(I) \&AVETW

DELTW(II)=STUTW

VWII I) OAVEFV

OELVN(II):STDFV

CHISU(II) CHITOT

TCON (I I) -TAU

$H(I I)=H C O R N$

HRIII THCORNR

RETUHN

END 
SUBPOUTINE RESULT

DIMENSION IRUN(25), TW(25), DELTW (25),VW(25), DELVW (25), CHISO(25)

OIMENSION TCON(25), H(25), HRIZS)

COMYON /BLKE/ IRUN, TW, DELTW, VW, OELLVW, CHISQ, TEON,H,HR

COHMON/GLKI/ II

COMYUN /BLK2/ TITLE $(2 O)$

COMYON /BLKA/ VNOM, HRSLPE

DIMENSION IRUNAC (25), TWAC (25), DELTWA (25), VWAC (25), DELVWA (25),

ICHISOA (25), TCONAC $(25)$, HACP (25), HRACP $(25)$

TNOY $=70$.

WRITE 16,2991 TITLE

199

FORMAT $(1 \mathrm{H}, 20 \mathrm{2}, 2044)$

WRITE 16,200 ,

200 FORMATIIX,1/10X,"SUMMARY OF RESULTS - OF ALL THE COOLING CURVES

I", $1 / 1$

WRITE 16,201,

201 FORMAT IIX,"RUN NO.",5X,"WATER TEMP,",3X,"RMS WAIER TEMP.",

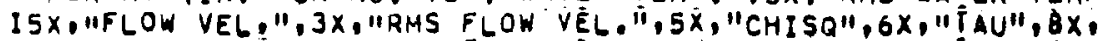

$2 " 14 ", 9 x, " 1 / 4 ", 11$

DO I $3=1$, II

WRITE $(6,202)$ IRUN(K),TW(K),UELTW(K),VW(K, DELVW(K)。

ICHISO $(K), T C O N(K), H(K), H R(K)$

202 FORYAT $11 x, 14,10 x, 57,4,8 x, 58,4,10 x, F 7,3,6 x, F 8,4,6 x, F 9,3$,

$12 x, F(, 3,3 x, 56,1,4 x, E 9,4)$

13 CONTÍNUE

$I A C=0$

DO $10 \quad J=1, I I$

$I A C=I A C+1$

IRUNAC (IAC) $=J$

TWAC (IAC) TW $(J)$

DELTWA I IAC) $=D E L T W(J)$

VWAC (I $A C)$ EW (J)

DELVWA (IAC) DDELVW(J)

CHISOA (IAC) BCHISO (J)

TCONAC (IAC) $=$ TCON (J)

HACP (IAC) $=H(J)$

HRACP (IAC) $: H R(J)$

10 CONTINUE

C COMPUTATION OF AVERAGES AND ERRORS ON AVERAGES -O-

C ALL THE COOLING CURVES ARE ACCEPTEO IN THIS PASS

SIIMTOO.

SUMV $\approx 0$.

SUMH:O.

SUMHR:O.

DO $30 \mathrm{M}=1, I A C$

SUMTESUMT † TWAC (M)

SUMVISUMV * VWAC (M)

SUMH=SUMH * HACP $(M)$

30

SUMHRISUMHR : HRACP (M)

CONTINUE

AVET = SUMT , IAC

AVEV = SUMV / IAC

AVE $H=$ SUMH, IAC

AVEHR= SUMHE / IAC

SUHSOT:O.

SUMSQV 0 .

SUMSOH:0. 
SMSAHR 0 ,

DO $31 \mathrm{~N}=1, I A C$

SUMSOT=SUMSOT - (TWAC (N) - AVET) * 2

SUMSOVASUMSOV - (VWAC (N) - AVEV) *

SUMSAHASUMSOH: (HACP(N) - AVEH) —

SMSOHR SMSOHR - (HAACP(N) - AVEHR) * 2

CONTINUE

$A=I A C+1$.

$B=1.1 A$

ERRTS=(SUMSOT/(IAC-1))

ERRVS = (SUMSQV / (IAC-1))

ERRHS ₹ (SUMSOH/ (IAC- 1$) ; \oplus 0$

ERRHRS (5MSQHR/ (IAC-1)) *B

ERRT $=$ SQRT (ERRTS)

ERRV $=$ SURT (ERRVS)

ERRH $=5$ STRT (ERRHS)

ERRHKaSQRT (ERRHRS)

WRITE $(6,80)$ II

FORMAT $1 / / 1,5 X, "$ TOTAL NO OF COOLING CURVES ANALYSED $\$ 11,131$

WRITE $(6,8])$ IAC

81 FORYAT (5X,"TOTAL NO OF ACCEPTED COOLING CURVES 811131

WRITE $(6,78)$

78 FORMATI5X," ALL THE COOLING CURVES ARE ACCEPTED IN THIS PASS " $/ 1$

WRITE $(6,82)$ AVET,ERRT

82 FORMAT $15 x$, "TEMP. OF WATER (IN C) "I, 56,3,2X, "PLUS OR MINUSI,

$12 \times, F 6,41$

WRITE $(6,93)$ AVEVIERRV

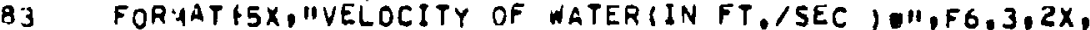

I"PLUS OR MINÜS", IX,F6,4, /

WAITE $(6,86)$ TNOM, VNOM, HRSLPE

86

FOR YAT I5X, "NORMALISATION TEMP, $=11, F B, 3,2 X, " O E G, F ", /$,

$15 X$, HOHMALISATION VELOCITY $=11, \dot{F} 8,3,2 \dot{X}, " F T, / 5 E C, 11,1$

$25 \times, 111 / H$ VS $1 /(V * *, \theta)$ SLOPE $=11, E 12,5,1 / 1$

WRITE $(0.84)$ AVEH.ERRH

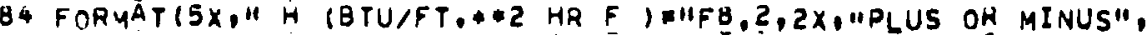
$1] x, F B, 21$

WRITE 16.85$)$ AVEHR, ERRHR

85 FORYATI5X,"I/H IFT.*2 HR F /BTU) :",EIZ,5.2X,

IIPLUS OR MINUS $1,2 X, E 12.5,1 / 1$

C

C RE-0O THE ABOVE AVERAGING WITH THE NEW ACCEPTANCE CRITERION

C REJECT a COOLING CURVE IF THE DEVIATION IÑ h FROM ITS MEAN IS MORE THA

C TWO STANDARO GEVIÁTIONS

HME ANEAVEH

HSI GMAASQRT (SUMSQH/(II-l))

$I A C=0$

DO $110 \mathrm{Jal}, \mathrm{II}$

HOVAABSI H(J) - HMEANI

TSTDAR IHOV/HSIGMA)

IF (TSTPAR .GT. Z.O , GO TO 110

IACIIAC *I

IRUVAC (IAC) $\equiv J$

TWAC (IAC) $=T W(J)$

DELTHA IIAC) $=$ DELTW(J)

VWAC (IAC) IVW(J)

DELVWA (IAC) =UELVW (J) 
71 FORMAT $11 x_{0}$ "RUN NO,",5x,"WATER TEMP,",3x, "RMS WATER TEMH.",

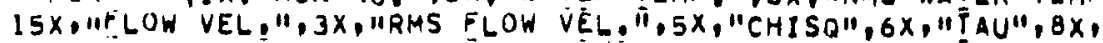
$2 " H ", 9 x_{1}, 1 / H^{\prime \prime, ~} / 1$

00 2乌 $L=1, I A C$

WRITE $(6,202)$ IRUNAC (L), TWAC (L), OELTWA(L),VWAC (L), UELVWA (L),

59 CONTINUE

C COMPUYATION OF AVERAGES ANO ERRORS ON AVERAGES - -

C ONLY ACCEPTED COOLING CURVES ARE USED

SUMT:0. SUMVan,

SUMH:O. SUMHK=0.

130 CONTINUE

AVET: SUMT, IAC

AVEV = SUHV / IAC

AVEH 2 SUMH / IAC

AVEHRE SUMHR / IAC

SUMSOTAO.

SUMSOV $\square 0$.

SUMSOHAO.

SMSOHR⿻0.

DO IJI $\mathrm{N}=1$, IAC

SUMSOT ZSUMSOT - (TWAC (N) - AVET) * 2

SUMSOV SUMSQV + (VWAC (N) - AVËV) * 2

SIMSOHASUMSOH * (HACP $(N)$ - AVEH) * 2

SMSAHR SMSQHR - (HRACP(N) - AVEHR) * *2

131 CONTINIIE

$A=I A C+I$.

$B=1,1 A$

ERRTSE (SUMSOT/ (IAC-1)) *B

ERRVS $=(5 U M S Q V /(I A C-1)) * 3$

$E R R H S=\{5 U M S Q H /(I A C-1)) \cdot B$

ERRHRS (SMSOHR/(IAC-2))*B

ERRT = SIRRT (ERHTS)

ERRV $=$ SORT (ERRVS)

ERRH $=$ SORT (ERRHS)

ERRHKESQRT (ERRHRS)

WRITE $(6,80)$ II

WRITE $(6,81)$ IAC

WRITE $(6,178)$

178 FOR AATISX,"REJECT A COOLING CURVE IF THE DEVIATION IN H FROM ITS

IMEAV IS MORE THAN TWO STANDARO JEVIATIONS",'I

WRITE $(6,82)$ AVET,ERRT

WRITE $(6,93)$ AVEVIERRV

WRITE $(6,86)$ TNOM,VNOM,HRSLPE

WR!TE $(0,84)$ AVEH,ERRH

WRITE $(6,85)$ AVEHR, ERRHR

RE TURN

ENO 


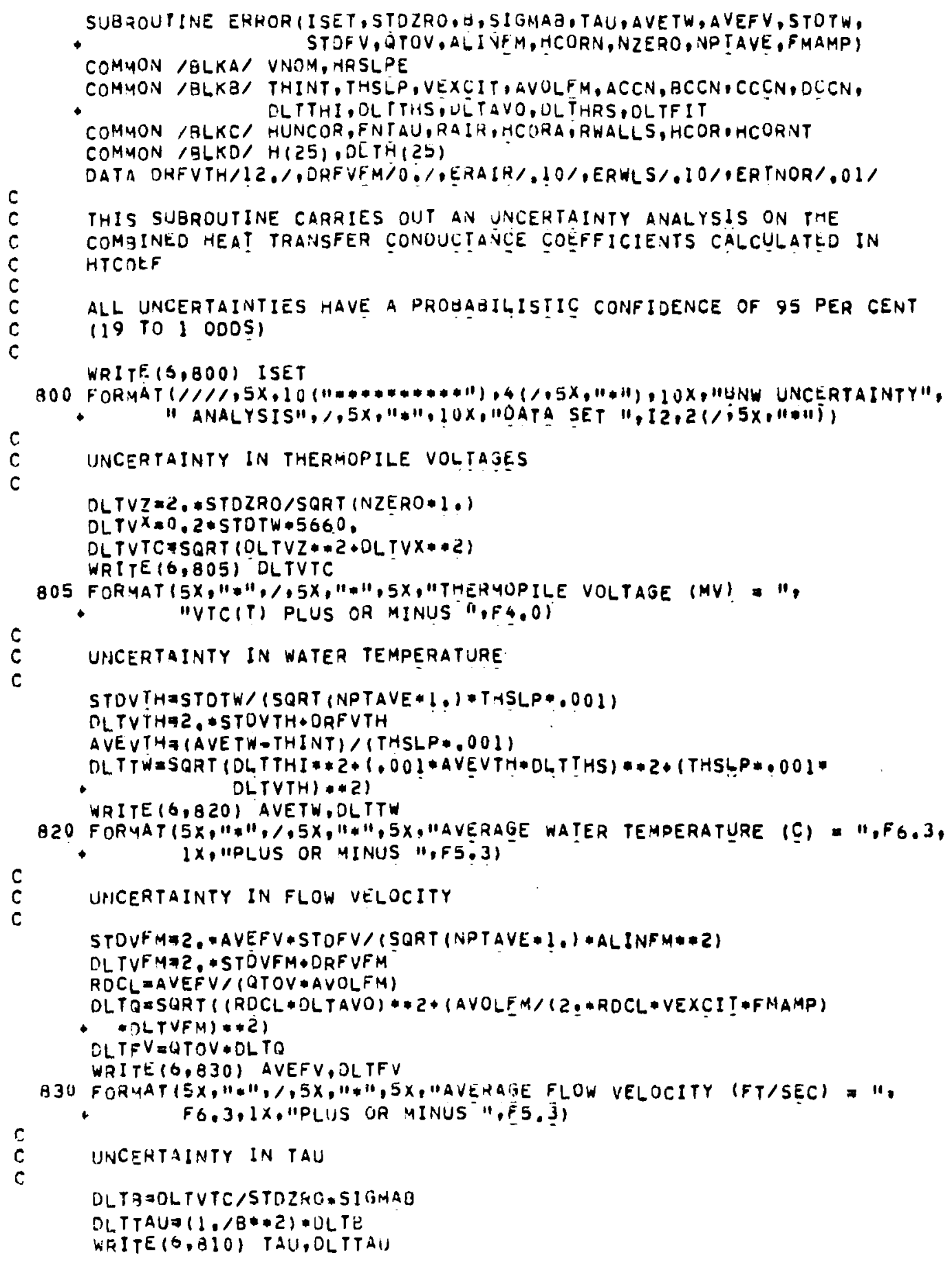




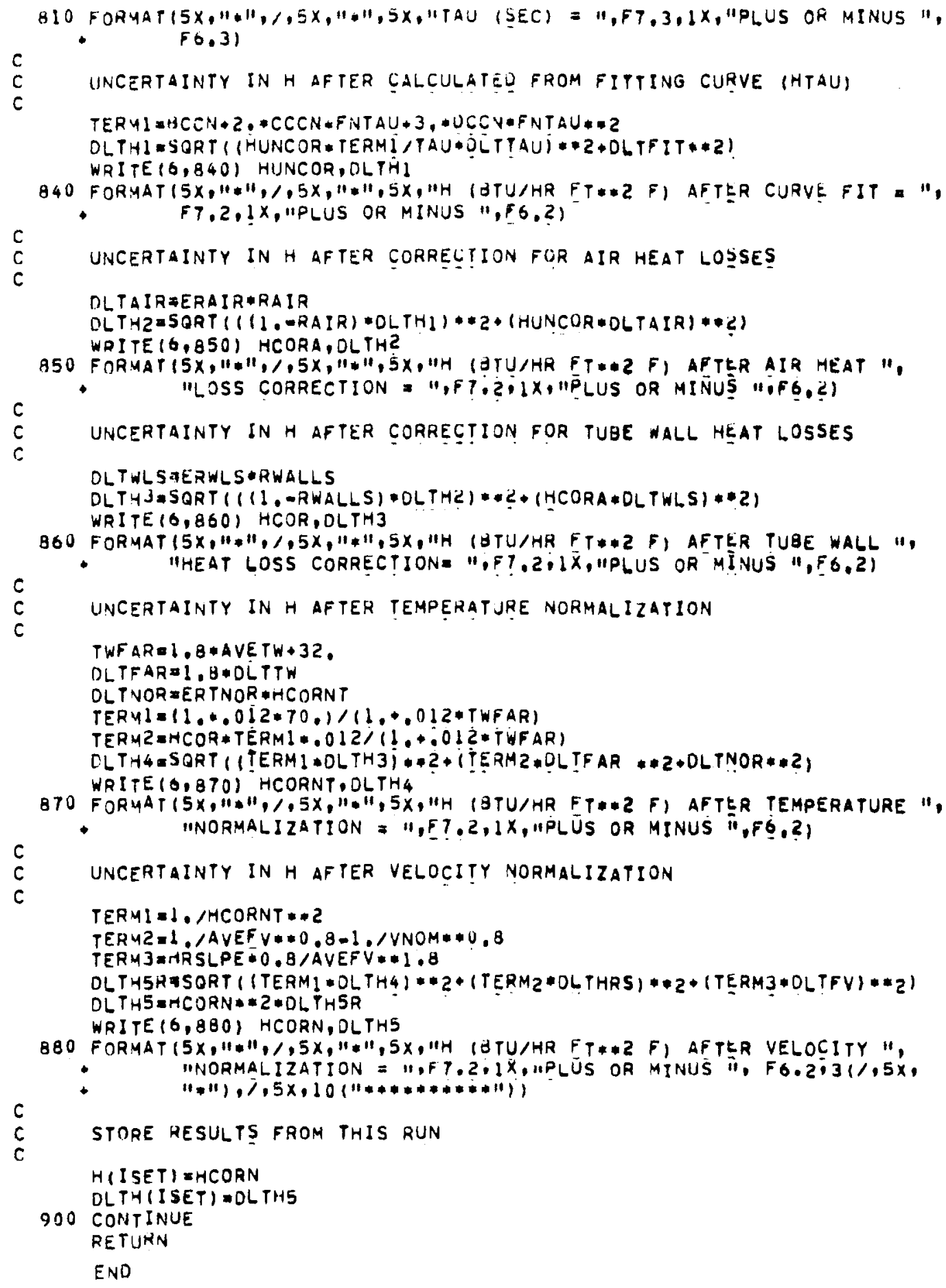




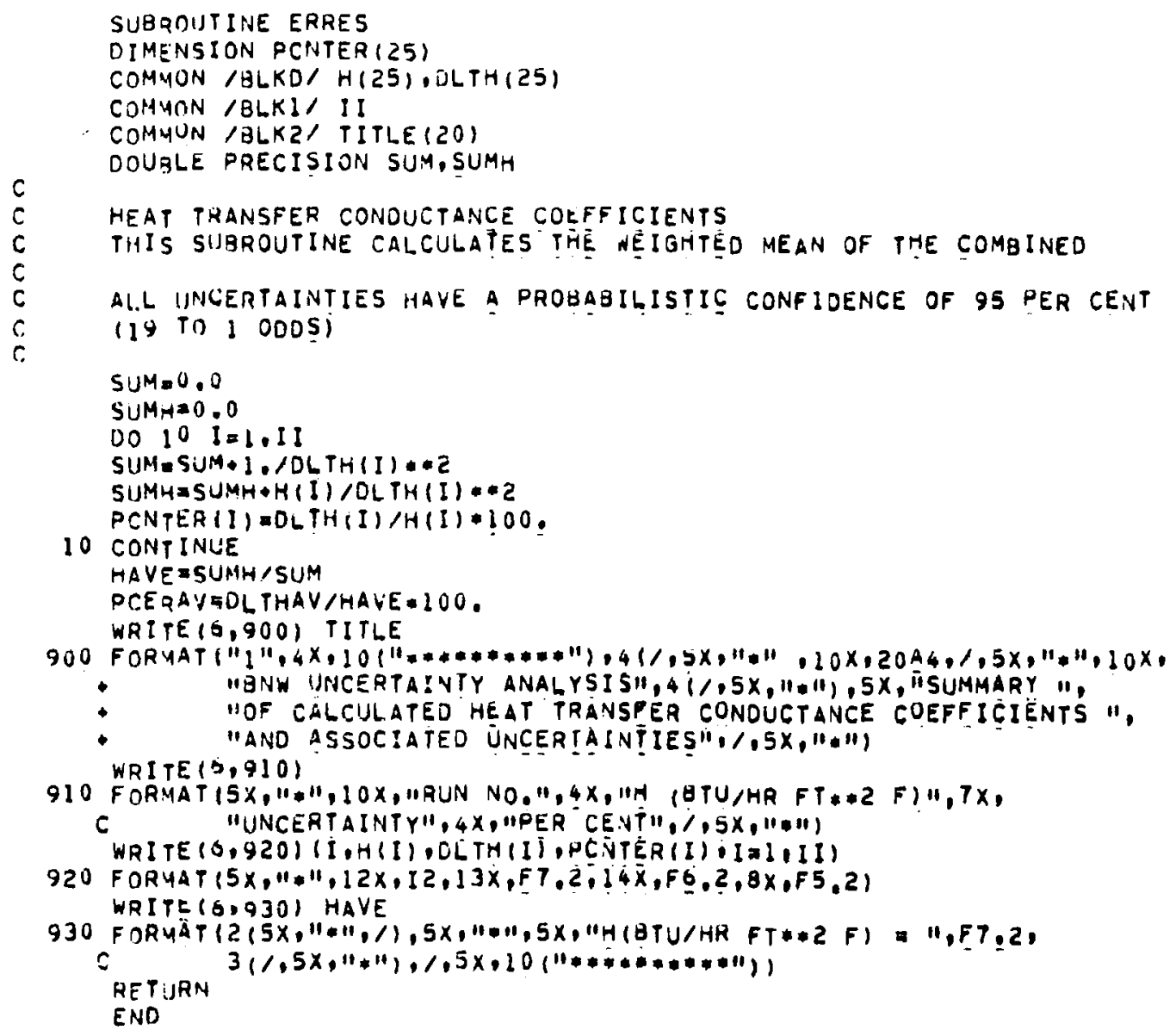


APPENDIX B

SAMPLE RESULTS 
Appendix $B$ contains sample results for five data sets each from the Keahole Point, Hawaii (p. B-2); St. Croix, Virgin Islands (p. B-5); and Gulf of Mexico tugboat (p. B-8) operations. Results include the conductance coefficient, conductance coefficient uncertainty, and percent conductance coefficient uncertainty values for each data run; and the weighted average conductance coefficients for each data set. 
APPENDIX B

SAMPLE RESULTS

Keahole Point, Hawaii Data

$\begin{aligned} \text { Data Set } 1- & 3 / 23 / 77, \text { Unit } A, \text { T I } B 337-76 \\ & \text { Nominal Velocity }=6.0 \mathrm{ft} / \mathrm{sec} .\end{aligned}$

\begin{tabular}{cccc} 
Run & $\begin{array}{c}H \\
\left.\text { Rutu/hr-ft }{ }^{2}-{ }^{\circ} F\right)\end{array}$ & $\begin{array}{c}\Delta H \\
\left.\text { (Btu/hr-ft }{ }^{2}-{ }^{\circ} \mathrm{F}\right)\end{array}$ & $\begin{array}{c}\Delta H / H \\
(\%)\end{array}$ \\
\cline { 2 - 3 } & 1030.55 & 23.01 & 2.23 \\
2 & 1020.61 & 29.34 & 2.87 \\
3 & 1059.73 & 55.16 & 5.21 \\
4 & 1029.70 & 23.44 & 2.38 \\
5 & 1022.12 & 21.14 & 2.07 \\
6 & 1029.98 & 19.62 & 1.90 \\
7 & 1022.91 & 20.98 & 2.05 \\
8 & 1062.53 & 29.13 & 2.74 \\
9 & 1021.52 & 22.10 & 2.16 \\
10 & 1020.10 & 25.68 & 2.52 \\
11 & 1019.42 & 21.98 & 2.16 \\
12 & 1032.21 & 22.49 & 2.18 \\
13 & 1038.64 & 37.39 & 3.60 \\
14 & 1026.10 & 20.76 & 2.02 \\
15 & 1035.29 & 20.02 & 1.93 \\
16 & 1022.50 & 27.31 & 2.67
\end{tabular}

$\overline{\mathrm{H}}=1028 \mathrm{Btu} / \mathrm{hr}-\mathrm{ft} \mathrm{t}^{2}{ }^{\circ} \mathrm{F}$

Data Set 2 - 3/30/77, Unit A, TI B337-76

Pipe lominal Velocity $=6.0 \mathrm{ft} / \mathrm{sec}$.

\begin{tabular}{|c|c|c|c|}
\hline Run & $\begin{array}{c}H \\
\left(B t u / h r-f t^{2}-{ }^{\circ} F\right) \\
\end{array}$ & $\begin{array}{c}\Delta H \\
\left(B t u / h r-f t^{2}-{ }^{\circ} \mathrm{F}\right) \\
\end{array}$ & $\begin{array}{l}\Delta H / H \\
(\%) \\
\end{array}$ \\
\hline 1 & 980.26 & 19.10 & 1.95 \\
\hline 2 & 977.38 & 18.86 & 1.93 \\
\hline 3 & 981.06 & 18.81 & 1.92 \\
\hline 4 & 978.11 & 18.72 & 1.9 \\
\hline 5 & 978.07 & 18.76 & 1.9 \\
\hline 6 & 983.79 & 19.03 & 1.9 \\
\hline 7 & 1005.63 & $*(a)$ & $\star$ \\
\hline 8 & 979.76 & 18.78 & 1.92 \\
\hline 9 & 982.78 & 18.90 & 1.92 \\
\hline 10 & 976.92 & 18.90 & 1.93 \\
\hline 11 & 980.93 & 18.90 & 1.93 \\
\hline 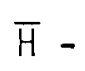 & $f t^{2}$ & & \\
\hline
\end{tabular}

(a) The asterisk indicates estimated conductance coefficient uncertainties of greater than $1000 \mathrm{Btu} / \mathrm{hr}-\mathrm{ft} 2-^{\circ} \mathrm{F}$ or $100 \%$. 
Data Set $3-5 / 02 / 77$, Unit B, AL 6061-T6

Pipe Nominal Velocity $=3.0 \mathrm{ft} / \mathrm{sec}$.

\begin{tabular}{|c|c|c|c|}
\hline Run & $\underset{\left(B t u / h r-f t^{2}-{ }^{\circ} F\right)}{H}$ & $\begin{array}{c}\Delta H \\
\left(B \leftarrow u / h r-f t^{2}-{ }^{\circ} F\right)\end{array}$ & $\begin{array}{l}\Delta \mathrm{H} / \mathrm{H} \\
(\%) \\
\end{array}$ \\
\hline $\begin{array}{r}1 \\
2 \\
3 \\
4 \\
5 \\
6 \\
7 \\
8 \\
9 \\
10 \\
11 \\
12 \\
13 \\
14 \\
15 \\
16\end{array}$ & $\begin{array}{l}531.56 \\
540.75 \\
529.99 \\
543.02 \\
523.11 \\
547.81 \\
527.39 \\
544.64 \\
530.62 \\
521.97 \\
545.39 \\
546.22 \\
549.40 \\
542.53 \\
540.50 \\
543.44\end{array}$ & $\begin{array}{r}8.38 \\
7.57 \\
8.46 \\
7.89 \\
6.98 \\
8.42 \\
7.06 \\
9.09 \\
8.56 \\
10.97 \\
8.63 \\
15.00 \\
9.18 \\
7.75 \\
7.22 \\
7.35\end{array}$ & $\begin{array}{l}1.58 \\
1.40 \\
1.60 \\
1.45 \\
1.33 \\
1.54 \\
1.34 \\
1.67 \\
1.61 \\
2.10 \\
1.58 \\
2.75 \\
1.67 \\
1.43 \\
1.34 \\
1.35\end{array}$ \\
\hline
\end{tabular}

Data Set 4 - 3/08/77, Unit C, A1 6061-T6

Pipe Nominal Velocity $=6.0 \mathrm{ft} / \mathrm{sec}$.

\begin{tabular}{|c|c|c|c|}
\hline Run & $\underset{\left(B t u / h r-f t^{2}-{ }^{\circ} F\right)}{H}$ & $\begin{array}{c}\Delta H \\
\left(B t u / h r-f t^{2}-{ }^{\circ} F\right)\end{array}$ & $\begin{array}{l}\Delta H / H \\
(\%)\end{array}$ \\
\hline 1 & 1117.85 & 15.56 & 1.39 \\
\hline 2 & 1118.95 & 12.61 & 1.13 \\
\hline 3 & 1118.49 & 13.30 & 1.19 \\
\hline 4 & 1129.62 & 13.95 & 1.23 \\
\hline 5 & 1116.25 & 12.77 & 1.14 \\
\hline 6 & 1111.34 & 14.83 & 1.33 \\
\hline 7 & 1123.17 & 12.75 & 1.08 \\
\hline 8 & 1118.09 & 12.25 & 1.10 \\
\hline 9 & 1118.46 & 12.32 & 1.10 \\
\hline 10 & 1114.63 & 12.29 & 1.10 \\
\hline 11 & 1117.64 & 12.73 & 1.14 \\
\hline 12 & 1117.19 & 12.19 & 1.09 \\
\hline 13 & 1121.93 & 12.46 & 1.11 \\
\hline 14 & 1118.10 & 12.54 & 1.12 \\
\hline 15 & 1122.81 & 12.61 & 1.12 \\
\hline 16 & 1119.90 & 14.04 & 1.25 \\
\hline & $r-f t^{2}-0$ & & \\
\hline
\end{tabular}


Data Set 5 - 3/16/77, Unit C, A1 6061-T6

Pipe Nominal Velocity $=6.0 \mathrm{ft} / \mathrm{sec}$.

\begin{tabular}{ccccc} 
Run & $\begin{array}{c}H \\
\left.\text { Btu/hr-ft }{ }^{2}-{ }^{\circ} \mathrm{F}\right)\end{array}$ & $\begin{array}{c}\Delta H \\
\left(B t u / h r-f t^{2}-{ }^{\circ} \mathrm{F}\right)\end{array}$ & $\begin{array}{c}\Delta H / H \\
(\%)\end{array}$ \\
\cline { 2 - 3 } & 1115.99 & 13.05 & 1.17 \\
2 & 1105.80 & 15.12 & 1.37 \\
3 & 1119.49 & 12.74 & 1.14 \\
4 & 1108.02 & 12.57 & 1.13 \\
5 & 1105.23 & 17.77 & 1.61 \\
6 & 1124.87 & 13.96 & 1.24 \\
7 & 1115.31 & 12.23 & 1.10 \\
8 & 1115.27 & 12.95 & 1.16 \\
9 & 1116.59 & 12.13 & 1.09 \\
10 & 1119.59 & 12.31 & 1.10 \\
11 & 1117.70 & 12.50 & 1.12 \\
12 & 1122.00 & 18.64 & 1.66 \\
13 & 1130.78 & 21.28 & 1.88 \\
14 & 1116.45 & 12.84 & 1.15 \\
15 & 1148.38 & 23.50 & 2.05 \\
16 & 1114.82 & 16.01 & 1.44 \\
$\bar{H}=1117$ Btu/hr-ft & ${ }^{\circ} \mathrm{F}$ & &
\end{tabular}


St. Croix, Virgin Islands Data

Data Set 1 - 7/24/77, Unit 1, A1 6061-T6

Pipe Nominal Velocity $=6.0 \mathrm{ft} / \mathrm{sec}$.

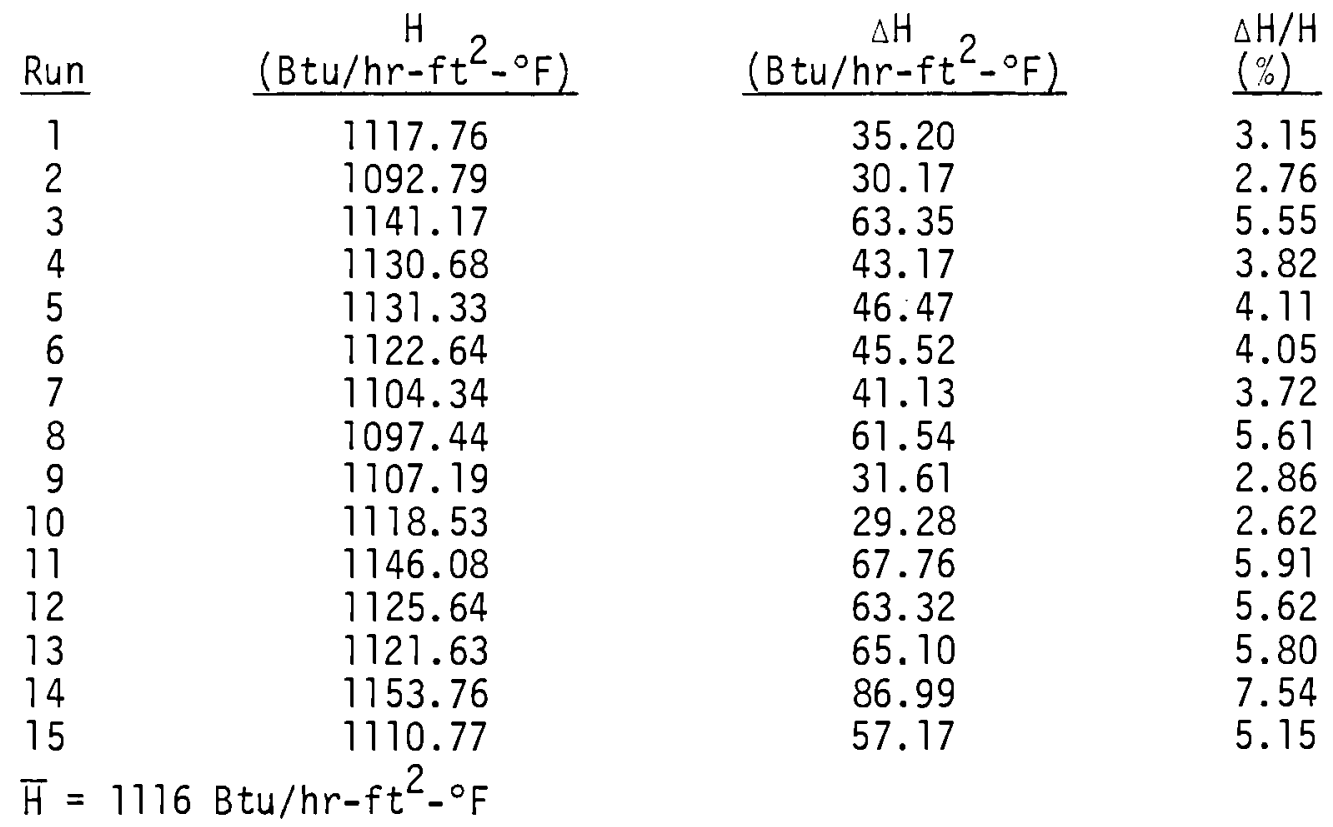

Data Set 2 - 7/30/77, Unit 1, A1 6061-T6

Pipe Nominal Velocity $=6.0 \mathrm{ft} / \mathrm{sec}$.

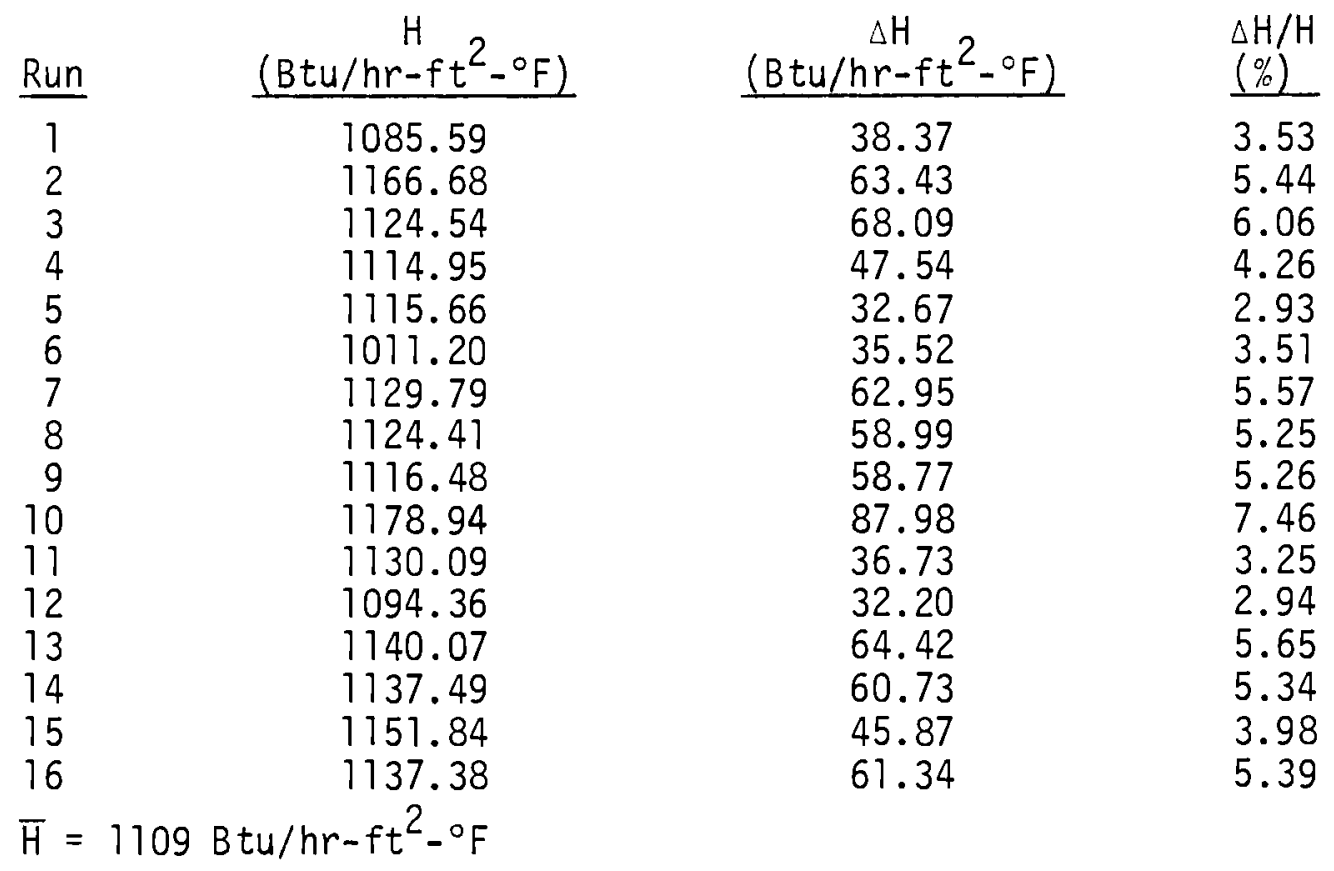


Data Set $3-8 / 05 / 77$, Unit 1, Al 6061-T6

Pipe Nominal Velocity $=6.0 \mathrm{ft} / \mathrm{sec}$.

\begin{tabular}{|c|c|c|c|}
\hline Run & $\begin{array}{c}H \\
\left(B t u / h r-f t^{2}-{ }^{\circ} F\right)\end{array}$ & $\begin{array}{c}\Delta H \\
\left(B t u / h r-f t^{2}-{ }^{\circ} F\right)\end{array}$ & $\begin{array}{r}\Delta H / H \\
(\%) \\
\end{array}$ \\
\hline $\begin{array}{r}1 \\
2 \\
3 \\
4 \\
5 \\
6 \\
7 \\
8 \\
9 \\
10 \\
11 \\
12 \\
13 \\
14 \\
15 \\
16\end{array}$ & $\begin{array}{l}1101.60 \\
1104.44 \\
1157.90 \\
1101.68 \\
1123.01 \\
1082.23 \\
1103.60 \\
1129.47 \\
1070.17 \\
1135.31 \\
1108.29 \\
1123.66 \\
1117.17 \\
1125.46 \\
1115.33 \\
1091.16\end{array}$ & $\begin{array}{l}27.95 \\
53.94 \\
44.73 \\
31.57 \\
41.25 \\
26.27 \\
39.43 \\
76.41 \\
43.56 \\
41.22 \\
52.99 \\
26.38 \\
37.65 \\
52.77 \\
58.65 \\
41.33\end{array}$ & $\begin{array}{l}2.54 \\
4.88 \\
3.86 \\
2.87 \\
3.67 \\
2.43 \\
3.57 \\
6.76 \\
4.07 \\
3.63 \\
4.78 \\
2.35 \\
3.37 \\
4.69 \\
5.26 \\
3.79\end{array}$ \\
\hline
\end{tabular}

$\bar{H}=1108 \mathrm{Btu} / \mathrm{hr}-\mathrm{ft} \mathrm{t}^{2}{ }^{\circ} \mathrm{F}$

Data Set $4-8 / 17 / 77$, Unit 1, A7 6061-T6 Pipe Nominal Velocity $=6.0 \mathrm{ft} / \mathrm{sec}$.

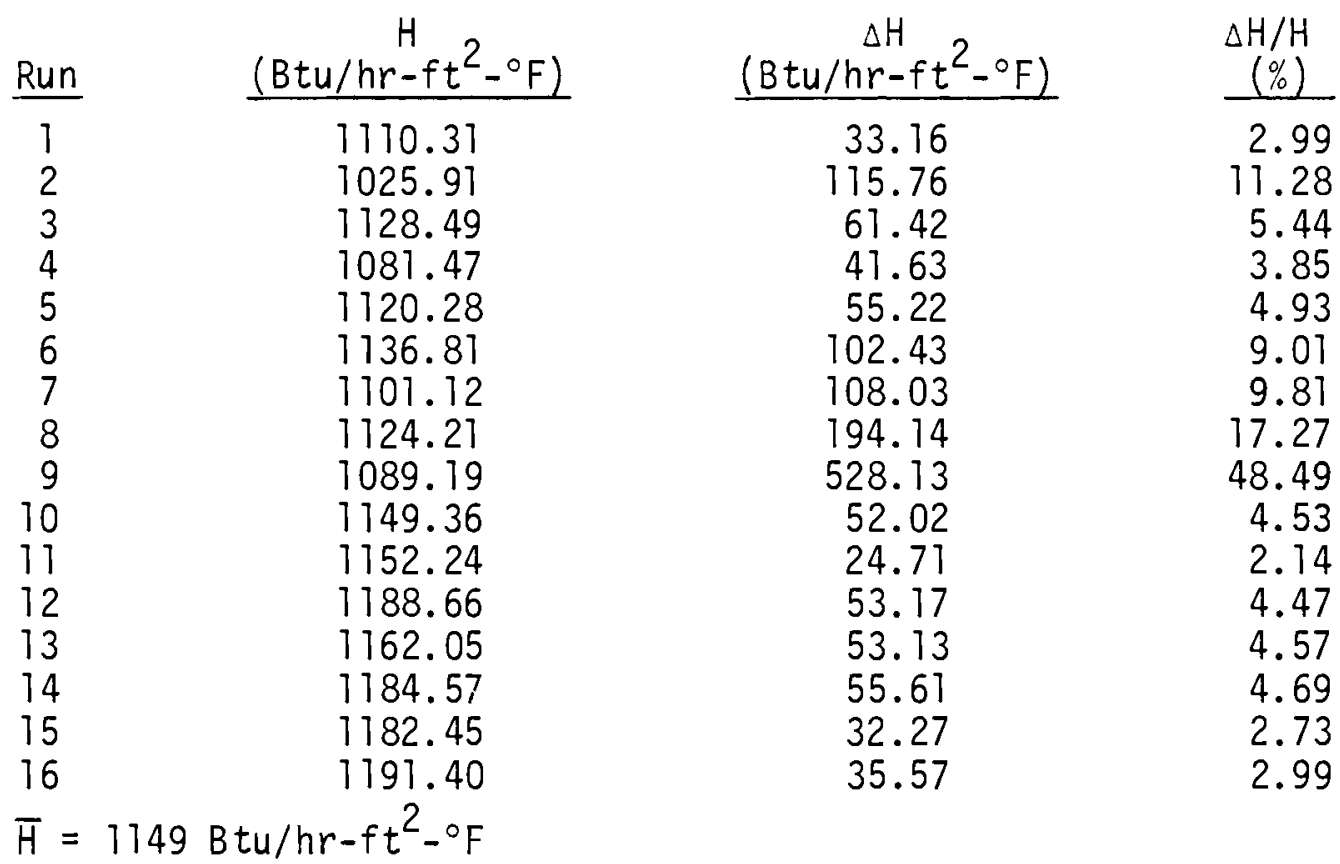


Data Set 5 - 9/26/77, Unit 1, A1 6061-T6

Pipe Nominal Velocity $=6.0 \mathrm{ft} / \mathrm{sec}$.

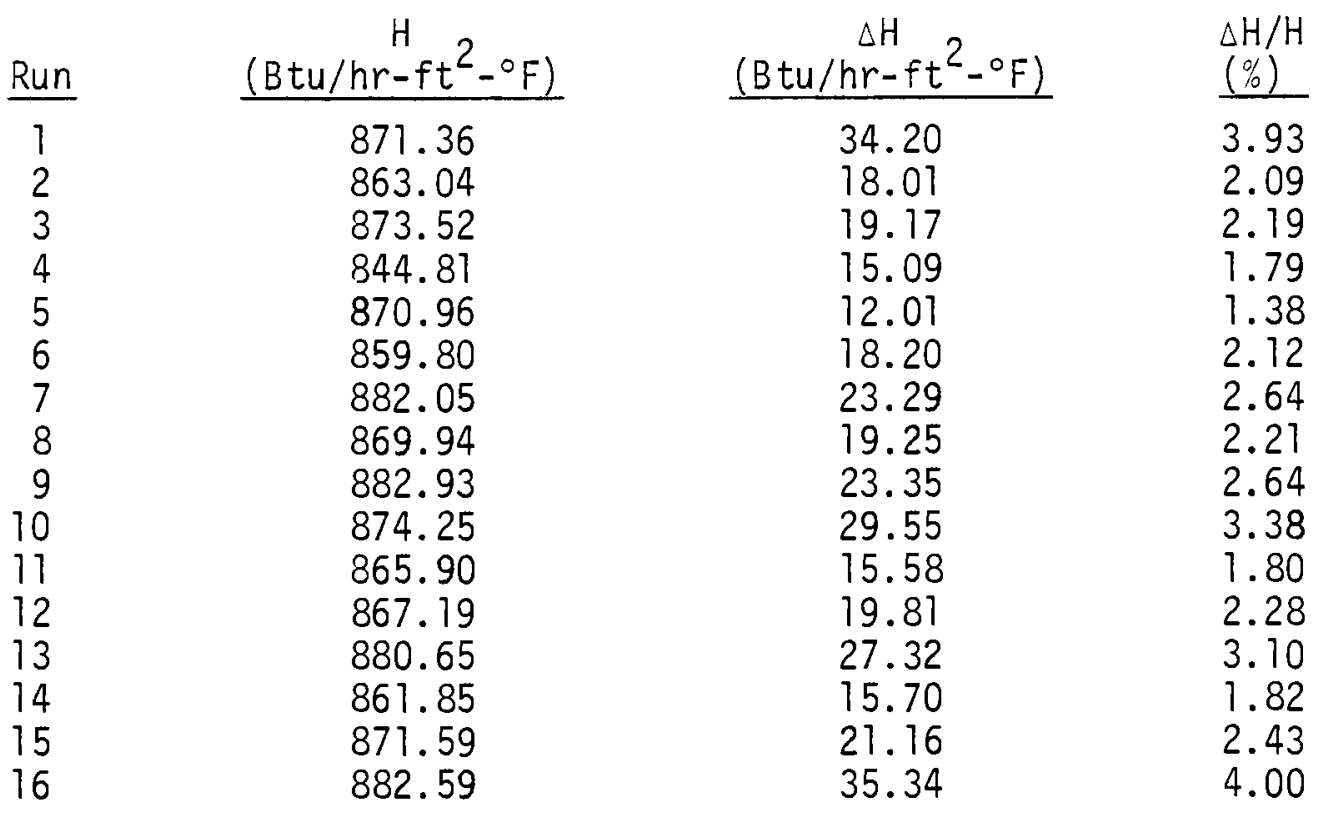


Gulf of Mexico Data

Data Set $1-11 / 14 / 77$, Unit 1 , A1 5052-0

Pipe Nominal Velocity $=6.0 \mathrm{ft} / \mathrm{sec}$.

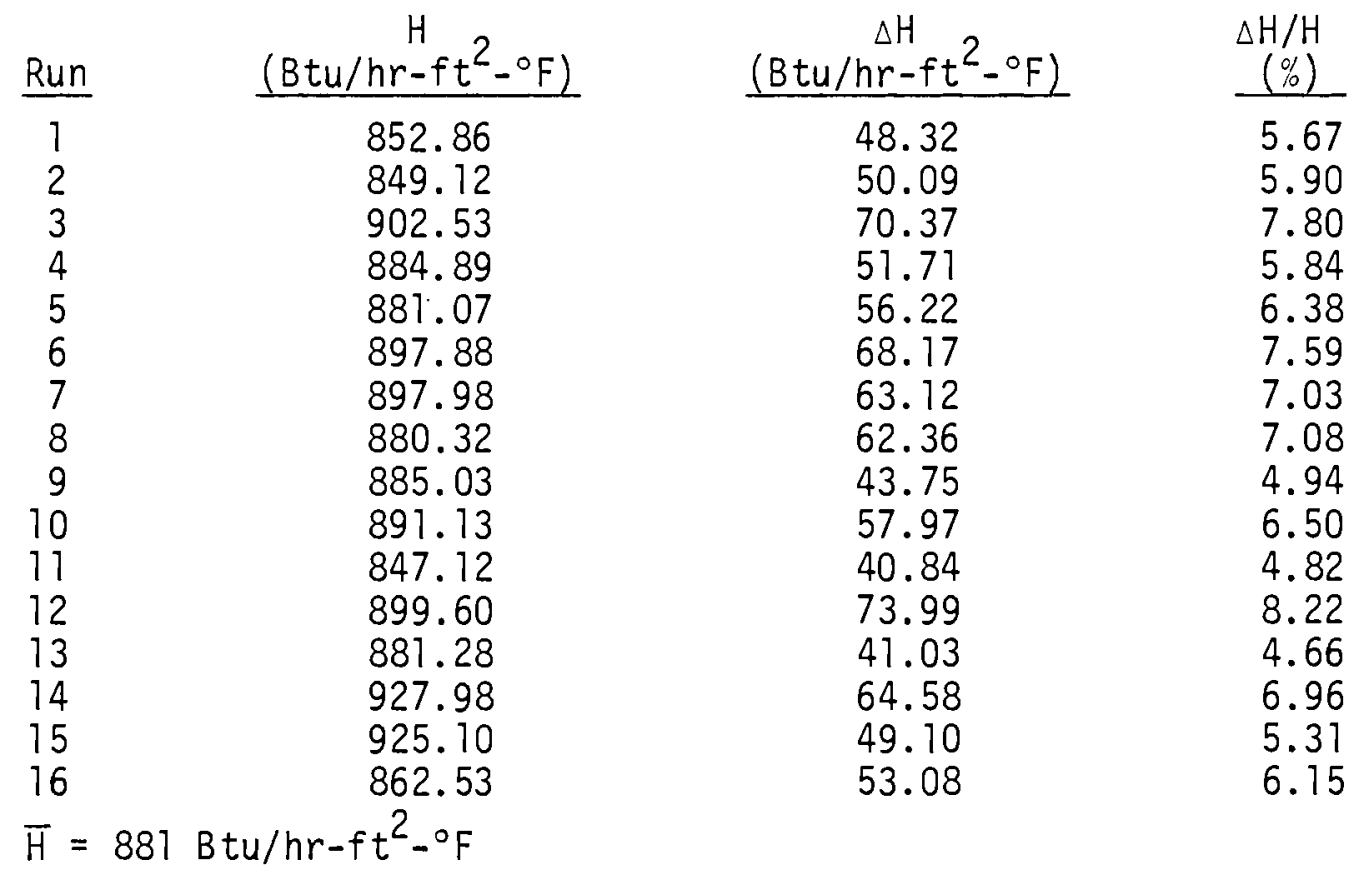

Data Set 2 - 11/20/77, Unit 1, A1 5052-0

Pipe Nominal Velocity $=6.0 \mathrm{ft} / \mathrm{sec}$.

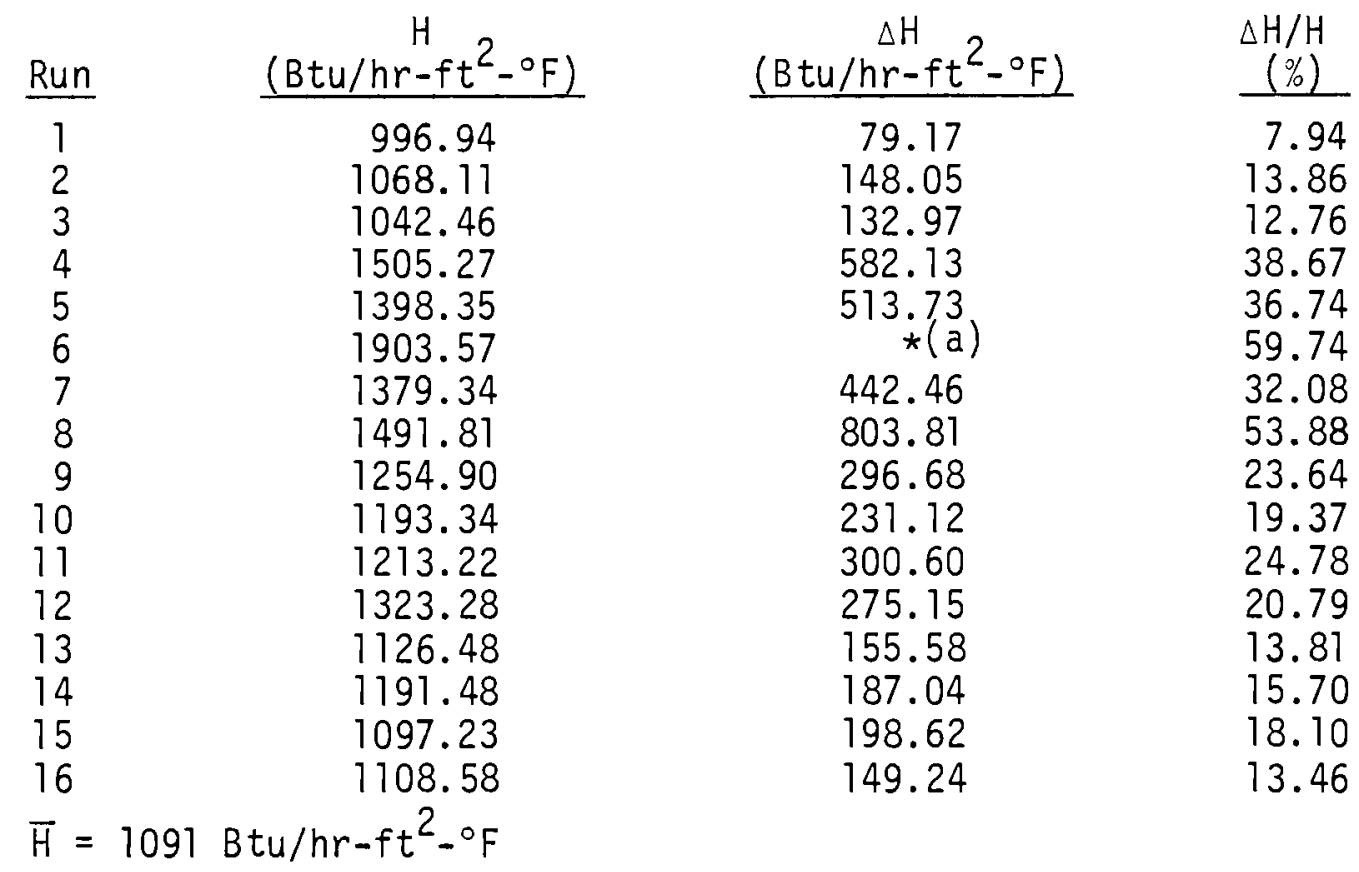

(a) The asterisk indicates estimated conductance coefficient uncertainties of greater than $1000 \mathrm{Btu} / \mathrm{hr}-\mathrm{ft}^{2}-{ }^{\circ} \mathrm{F}$ or $100 \%$. 
Data Set $3-11 / 21 / 77$, Unit 2, A1 5052-0

Pipe Nominal Velocity $=3.0 \mathrm{ft} / \mathrm{sec}$.

\begin{tabular}{cccc} 
Run & $\begin{array}{c}H \\
\left(B t u / h r-f t^{2}-{ }^{\circ} \mathrm{F}\right)\end{array}$ & $\frac{\Delta H}{\left(B t u / h r-\mathrm{ft}^{2}-{ }^{\circ} \mathrm{F}\right)}$ & $\begin{array}{c}\Delta H / H \\
(\%)\end{array}$ \\
\hline 1 & 537.62 & 43.77 & 8.14 \\
2 & 513.15 & 35.00 & 6.82 \\
3 & 552.22 & 47.67 & 8.63 \\
4 & 558.43 & 50.35 & 9.02 \\
5 & 551.89 & 32.39 & 5.87 \\
6 & 524.66 & 41.50 & 7.91 \\
7 & 548.29 & 54.61 & 9.96 \\
8 & 515.75 & 34.82 & 6.75 \\
9 & 539.00 & 38.85 & 7.21 \\
10 & 517.01 & 30.87 & 5.97 \\
11 & 520.69 & 38.22 & 7.34 \\
12 & 552.47 & 30.78 & 7.38 \\
13 & 516.76 & 55.94 & 7.69 \\
14 & 526.88 & 39.63 & 10.62 \\
15 & 505.19 & 43.07 & 7.61 \\
16 & 50.57 & & 8.53 \\
$\bar{H}=529 \mathrm{Btu} / \mathrm{hr}-\mathrm{ft}^{2}-{ }^{\circ} \mathrm{F}$ & &
\end{tabular}

Data Set $4-12 / 05 / 77$, Unit 2, A7 5052-0

Pipe Nominal Velocity $=3.0 \mathrm{ft} / \mathrm{sec}$.

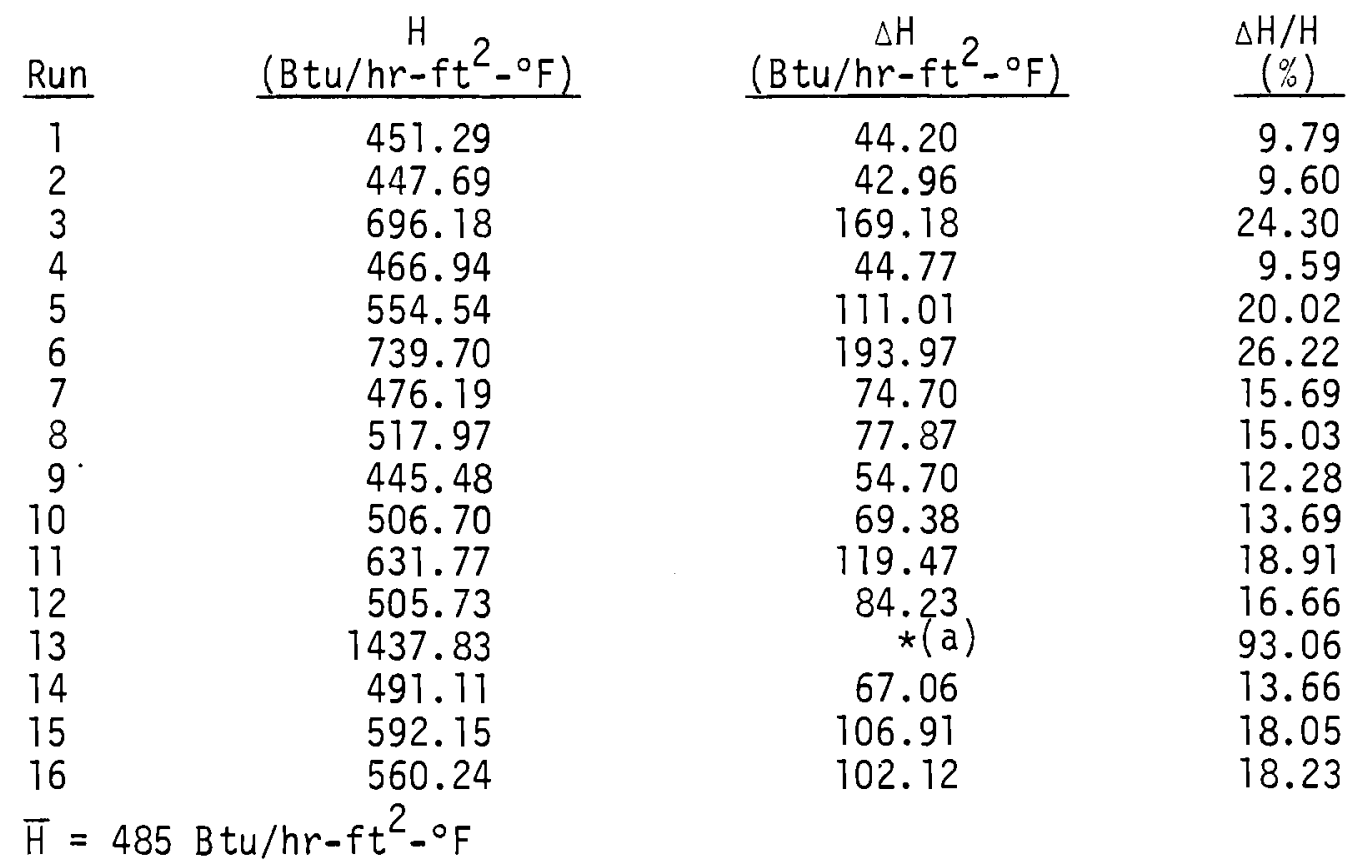

(a) The asterisk indicates estimated conductance coefficient uncertainties of greater than $1000 \mathrm{Btu} / \mathrm{hr}-\mathrm{ft} \mathrm{t}^{2}{ }^{\circ} \mathrm{F}$ or $100 \%$. 


$\begin{array}{cc}\text { Data Set } 5 & \begin{array}{c}\text { 12/08/77, Unit } \\ \text { Pipe Nominal Ve }\end{array} \\ \frac{\text { Run }}{1} & \frac{\left(\text { Btu/hr-ft }{ }^{2}-{ }^{\circ} \mathrm{F}\right)}{201.32} \\ 2 & 475.93 \\ 3 & 521.21 \\ 4 & 512.85 \\ 5 & 521.07 \\ 6 & 538.11 \\ 7 & 494.66 \\ 8 & 486.15 \\ 9 & 557.42 \\ 10 & 520.03 \\ 11 & 478.89 \\ 12 & 470.88 \\ 13 & 585.91 \\ 14 & 517.02 \\ 15 & 505.49 \\ 16 & 625.46 \\ \bar{H}=502 \text { Btu/hr-ft }{ }^{\circ}{ }^{\circ} \mathrm{F}\end{array}$

\begin{tabular}{cr}
$\begin{array}{cr}\Delta H \\
\left(B t u / h r-f t^{2}-{ }^{\circ} F\right)\end{array}$ & $\begin{array}{r}\Delta H / H \\
(\%)\end{array}$ \\
\cline { 1 - 2 } 54.09 & 10.79 \\
47.35 & 9.95 \\
68.33 & 13.11 \\
51.61 & 10.06 \\
77.74 & 14.92 \\
81.14 & 15.08 \\
48.37 & 9.78 \\
37.93 & 7.80 \\
83.17 & 14.92 \\
57.84 & 11.12 \\
42.30 & 8.83 \\
48.30 & 10.26 \\
107.62 & 18.37 \\
63.93 & 12.36 \\
65.31 & 12.92 \\
107.16 & 17.13
\end{tabular}




\section{DISTRIBUTION}

Ho. of

Copies

OFFSITE

A. A. Churm

U.S. Department of Energy

Chicago Patent Group

9800 South Cass Avenue

Argonne, IL 60439

27 DOE Technical

Information Center

E. Adams

Massachusetts Institute of Technology

MIT 48-315

Cambridge, MA 02139

J. H. Anderson

Sea Solar Power, Inc.

1615 Hillock Lane

York, PA 17403

R. A. Barry

Hydronautics, Inc.

7210 Pindell School Road

Laure1, MD 20810

E. J. Barsneff

Westinghouse Electric Corp.

P.0. Box 9175, N-206

Philadelphia, PA 19113

N. Basar

M. Rosenblatt \& Son, Inc.

350 Broadway

New York, NY 10013

K. J. Bell

School of Chemical

Engineering

Oklahoma State University

Stillwater, OK 74074

R. A. Bonewitz

Aluminum Company of America

Alcoa Technical Center

Alcoa Center, PA 15069
No. of

Copies
W. K. Boyd

Corrosion \& Electrochemical

Technology Section

Chemistry Department

Battelle Columbus Laboratories

505 King Avenue

Columbus, $\mathrm{OH} 43201$

D. Brenning

Lockheed Center for

Marine Research

6350 Yarrow Drive

Carlsbad, CA 92008

C. Bretschneider

Bretschneider Consultants

2600 Pualani Way

Honolulu, HI 96815

V. J. Castelli

Ocean Environment and

Fouling Branch, Code 2853,

Naval Ship Research and

Development Center

Annnapolis Laboratory

Annapolis, MD 21402

W. A. Corpe

Department of Biological

Sciences

Columbia University

New York, iNY 10027

H. L. Craig, Jr.

Division of Ocean

Engineering

School of Marine and Atmospheric Science

University of Miami

10 Rickenbacker Causeway

Miami, FL 33149 
No. of

Copies

J. De Palma

Code 3432

Roon C-316, B]dg. 1105

U.S. Naval Oceanographic Office

Bay St. Louis, MS 39522

S. C. Dexter

College of Marine Sciences Complex

University of Delaware

Lewes, DE 19958

J. J. Ditmars

Argonne National Laboratory

Energy \& Environmental

Division

9700 South Cass Avenue

Argonne, IL 60439

R. H. Douglass

TRW Inc., DSSG

One Space Park

Building 81, Room 1538

Redondo Beach, CA 90278

J. E. Draley

Argonne National Laboratory

9700 South Cass Avenue

Argonne, IL 60439

R. W. Drisko

Materials Science Division

Civi] Engineering Laboratory, NCBC

Port Hueneme, CA 93043

P. Duncan

Tetra Tech, Inc.

1911 No. Fort Myer Drive

Arlington, VA 22209
No. of

Copies

J. G. Fetkovich

Department of Physics

Carnegie-Mellon University

Schenley Park

Pittsburgh, PA 15213

M. D. Fraser

Intertechnology Corporation

1001 Main Street

Warrenton, VA 22186

C. I. Gibson

Marine Biology Program Leader

Marine Research Laboratory

Route 5, Box 1000

Sequim, WA 98382

D. P. Gregory

Energy Analysis

Institute of Gas Technology

3424 S. State Street

ITT Center

Chicago, IL 60616

S. Gronich

Department of Energy

Division of Solar Technology

600 E Street N.W.

Washington, DC 20545

E. C. Haderlie

Oceanography Department

Nlaval Postgraduate School

Monterey, CA 93940

P. H. Hadley, Jr.

Gibbs \& Cox, Inc.

40 Rector Street

New York, NY 10006

D. T. Hamilton, Jr.

AES/DBER

Department of Energy

Washington, DC 20545 
No. of

Copies

A. J. Haskel

Society of Naval Architects and Narine Engineering

Suite 1369, One World Trade Center

New York, NY 10048

D. T. Hove

Science Applications, Inc.

One Continental Plaza, Suite 310

101 Continental Boulevard

El Segundo, CA 90245

E. F. Johnson

National Oceanographic Data Center

2001 Wiscons in Ave., N.W.

Washington, DC 20235

E. H. Kinelski

Division of Solar Technology

Department of Energy

600 E Street N.W.

Washington, DC 20545

J. G. Knudsen

Engineering Experiment Station

Covell Hall 219

Oregon State University

Corvallis, OR 97331

R. E. Lacey

Southern Research Institute

Birmingham, AL 35205

F. L. La Que

Claridge House

Apartment 803

Claridge Drive

Verona, NJ 07044

A. Lavi

Division of Solar Technology

Department of Energy

600 E Street N.W.

Washington, DC 20545 iio. of

Copies

L. F. Lewis

Division of Solar Technology

Department of Energy

600 E Street N.W.

Washington, DC 20545

B. Little

NORDA - NSPL

B1dg. 1105

Bay St. Louis, MS 39520

T. E. Little

Westinghouse Electric

Corporation

Oceanic Division

P.0. Box 1488

Annapol is, MD 21404

R. N. Lyon

Energy Division

Oak Ridge National Laboratory

P.0. Box $X$

Oak Ridge, TN 37830

R. Makofski

Applied Physics Laboratory

Johns Hopkins University

Laure1, MD 20810

F. Mathews

Colorado School of Mines

Golden, CO 80401

J. W. Mavor, Jr.

Woods Hole Oceanographic

Institution

Woods Hole, MA 02543

W. R. McCluney

Florida Solar Energy Center

300 State Road 401

Cape Canaveral, FL 32920

M. McCormick

U.S. Naval Academy

Annapolis, MD 21402 
No. of

Copies
No. of

Copies

\author{
J. McGowan \\ Mechanical Engineering \\ Department \\ University of Miassachusetts \\ Amherst, MA 01002 \\ J. W. Michel \\ OTEC Heat Exchange Project \\ Activity \\ Union Carbide Nuclear \\ Division \\ Oak Ridge National \\ Laboratories \\ Box Y \\ Oak Ridge, TN 37830 \\ R. Mi tchell \\ Harvard University \\ Pierce Hall \\ Cambridge, MA 02138 \\ R. L. Molinari \\ NOAA/AOML \\ 15 Rickenbacker Causeway \\ Mi ami, FL 33149 \\ F. C. Munchmeyer \\ Department of Mechanical \\ Engineering \\ University of Hawai \\ 2540 Dole Street \\ Honolulu, HI 96822 \\ J. H. Nath \\ Department of Mechanical \\ Engineering \\ Oregon State University \\ Corvallis, OR 97331
}

M. E. Nelson

United States Naval Academy

Annapol is, 化 21402

J. Nicol

Physical Systems Section

Arthur D. Little, Inc.

28 Acorn Park

Cambridge, MA 02140
J. M. Nilles

University of Southern

California

University Park

Los Angeles, CA 90007

F. Notaro

Union Carbide Corporation

Linde Division

Oak Ridge National

Laboratories

P.0. Box 4

Oak Ridge, TN 37830

S. A. Piacsek

U.S. Naval Research Laboratory

4555 Overlook Avenue

Washington, DC 20375

D. Price

U.S. National Oceanic and Atmospheric Administration 6010 Executive Blvd.

Rockville, NiD 20852

F. X. Remond

Engineering Consultant

Sperry Rand

Space Support Division

Mississippi Test Facility

Bay St. Louis, MS 39520

S. Ridgeway

$R$ \& D Associates

P.0. Box 9695

Marina del Rey, CA 90291

R. Rothfus

Department of Chemical

Engineering

Carnegie-Mellon University

Schenley Park

Pittsburgh, PA 15213 
No. of

Copies

J. F. Rynewicz

Oceân Systemis

Research \& Development

Division

Lockheed Missiles and

Space Company, Inc.

ORGN. 57-20, Euilding 150

1111 Lockheed Way

Sunnyvale, CA 94088

E. W. Saaski

Sigrna Research, Inc.

2952 George Washington Way

Richland, WA 99352

C. M. Sabin

Geoscience, Ltd.

$410 \mathrm{~S}$. Cedros Avenue

Solana Beach, CA 92075

D. Sands

Interstate Electronics Corp.

707 E. Vermont Road

Anaheim, CA 92850

J. Sandusky

Energy \& Environment Division

Lawrence Eerkeley Laboratory

University of California

Berkeley, CA 94720

N. S. Sather

Argonne National Laboratory

9700 South Cass Avenue

Argonne, IL 60439

H. H. Sephton

College of Engineering

Office of Research Services

University of California

Berkeley, CA 94720
No. of

Copies

W. T. Sheppard

NOAA Data Buoy Office

National Space Technology Laboratories

Bay St. Louis, MS 39529

W. Sherwood

Division of Solar Technology

Department of Energy

600 E Street N.W.

Washington, DC 20545

E. A. Silva

Ocean Facilities Program Office

Naval Facilities Engineering Command

Hoffman Building \#2

200 Stovall Street

Alexandria, VA 22332

W. Smith

Division of Solar Technology

Department of Energy

600 E Street N.W.

Washington, DC 20545

F. A. Spiehler

INDBO OTEC-2 Program Manager

INOAA Data Buoy Office

National Space Technology Laboratories

Bay St. Louis, MS 39529

W. R. Suratt

DSS Engineers, Inc.

7483 Northwest 4 th Street

Fort Lauderdale, FL 33317

E. J. Tachupp

General Electric Company/TEMPO

777 Fourteenth Street N.W.

Washington, DC 20005

D. L. Thomas

Ichthyological Associates, Inc.

Box 70-D, R. D. 2

West Brook Lane

Absecon, NJ 08201 
No. of

Copies

J. B. Thomasian

Energy and Environmenta] Analysis, Inc.

1701 No. Fort Myer Drive

Suite 1213

Arlington, VA 22209

L. C. Trimble

Lockheed Missiles and

Space Company, Inc.

P. 0. Box 504

Sunnyvale, CA 94088

H. P. Vind

Materials Science Division

Civi] Engineering Laboratory

Naval Construction Battalion Center

Port Hueneme, CA 93043

0. Von Zweck

Department of Oceanography and Ocean Engineering

Florida Institute of Technology

Melbourne, FL 32901

F. Vukovich

Research Triangle Institute

Research Triangle Park, NC 27709

G. Wick

Institute of Marine Resources

University of California

at San Diego

La Jolla, CA 92093

P. Wilde

University of Cal ifornia

438 Hearst Mining Building

Berkeley, CA 93940

P. Wolff

Ocean Data Systems, Inc.

6000 Executive Blvd.

Rockville, MD 20852
No. of

Copies

\section{Zener}

Carnegie-Mellon University

Schenley Park

Pittsburgh, PA 15213

ONSITE

2 DOE Richland Operations Office Energy Programs Division

G. L. Liffick

H. E. Ransom

51 Battelle-Northwest

S. P. Bird (5)

J. M. Creer

R. H. Gray

A. J. Haverfield

G. A. Jensen

W. W. Laity

R. G. Moles

R. E. Nightingale

R. W. Pennington

L. D. Perrigo (30)

A. M. Sutey

G. E. Zima

Technical Information (5)

Technical Publications 